Supporting Information

\title{
Online HPLC Analysis of Buchwald-Hartwig Aminations from Within an Inert Environment
}

Thomas C. Malig, Lars P. E. Yunker, Sebastian Steiner, Jason E. Hein*

Department of Chemistry, University of British Columbia, 2036 Main Mall, Vancouver, British Columbia V6T 1Z1, Canada

*jhein@chem.ubc.ca

\section{Contents}

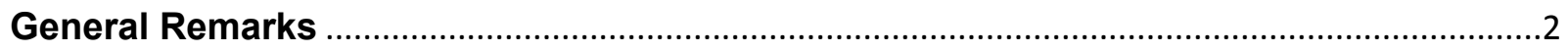

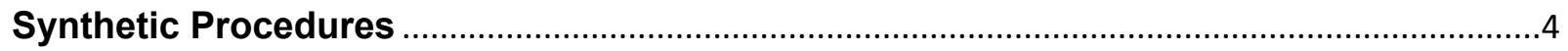

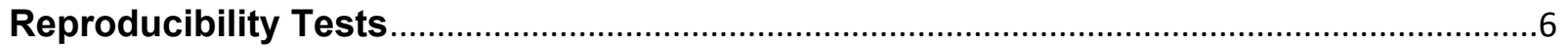

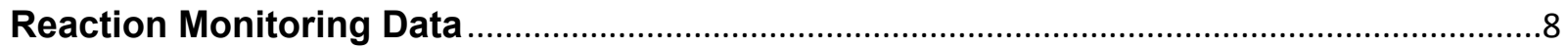

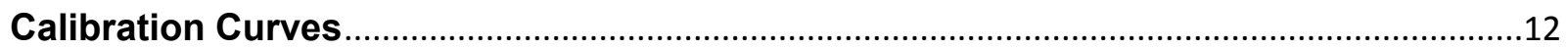

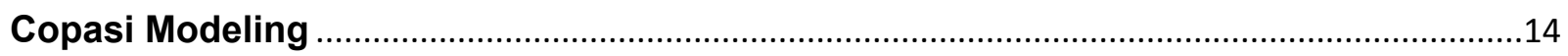

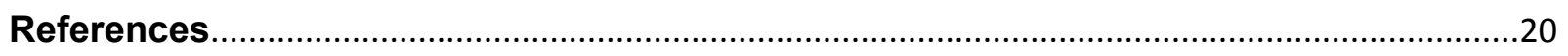

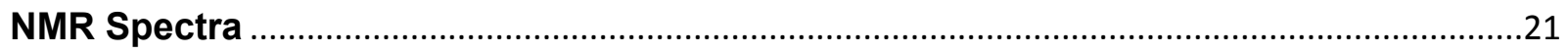




\section{General Remarks \\ Reagents}

Bis(4-methoxyphenyl)amine was purchased from AKScientific and used as received. Palladium(II) acetate, tri-tert-butylphosphine, iodobenzene, bromobenzene, 1-bromo-4iodobenzene, and LiHMDS were purchased from Sigma Aldrich and were used as received. All other reagents and solvents were purchased from conventional suppliers and used as received unless otherwise stated. Silica gel was purchased from Silicycle ( $60 \AA, 230 \times 400$ mesh).

\section{Analytical Methods}

NMR spectra were recorded on a Bruker AV-400 for ${ }^{1} \mathrm{H}$, and ${ }^{13} \mathrm{C}$ and were referenced to the residual solvent peak. ${ }^{1}$ The abbreviations s, d, t, q, m signify singlet, doublet, triplet, quartet, and multiplet, respectively. NMR spectra were analyzed by using the software MNova.

The Liquid Chromatography (LC) samples were analyzed by HPLC/MS conducted on an Agilent $1200 \mathrm{HPLC}$ with the following configuration:

Agilent G1379B degasser, G1312A binary pump, G1316A thermal column compartment, diode array detector and a 6120 single quad mass spectrometer.

Analytical setting for the detectors are:

DAD $-200-400 \mathrm{~nm}$ collected at $20 \mathrm{~Hz}$ storing all spectra for offline analysis. Peak area for quantification varies depending on the experiment, see calibration curves for details

ESI-MSD - positive mode scan for $\mathrm{m} / \mathrm{Z} 110-1500$ running at 0.8 sec/cycle. drying gas $=$ $7.0 \mathrm{l} / \mathrm{min}$, nebulizer pressure $=20 \mathrm{psi}$, gas temperature $=300^{\circ} \mathrm{C}$, capillary voltage $=4000 \mathrm{~V}$

HPLC column and mobile phase method used the follow conditions: Poroshell C18, $2.1 \times 50 \mathrm{~mm}, 2.7-$ Micron Column; Temperature $=25^{\circ} \mathrm{C}$; Solvent $A=$ Water, $0.1 \%$ Formic Acid; Solvent $B=$ acetonitrile; Flow Rate $=0.625 \mathrm{~mL} / \mathrm{min}$; Starting Conditions $=70 \%$ A, $30 \%$ B; $0.00-5.00$ min gradient to $30 \%$ A, $70 \%$ B; $5.00-5.80$ min isocratic $30 \% A, 70 \% B ; 5.80-8.00$ min gradient to $0 \% A, 100 \% B$

\section{Default Sampling Method:}

Temporal HPLC data was obtained using a modified reaction monitoring platform similar to which has been reported in our group previously. ${ }^{2}$ All sampling events were executed by an Arduino microcontroller which was controlled via a Python script. The sampling sequence begins by actuating the Easysampler to extend the sampling pocket into the reaction mixture. After 5 seconds the pocket is retracted and THF (standard volume $=700 \mu \mathrm{L}$ ) is delivered (default flow rate $=1.0 \mathrm{~mL} / \mathrm{min}$ ) through the Easysampler, out of the nitrogen filled glovebox, and onto the injection valve for analysis by HPLC. The injection valve is then triggered aligning the reaction aliquot with the HPLC pump and column allowing for online analysis. The sampling lines are then flushed with THF $(2.0 \mathrm{~mL}, 1.0 \mathrm{~mL} / \mathrm{min})$ before reinitiating the sampling sequence. The Python sampling script is available on request. 


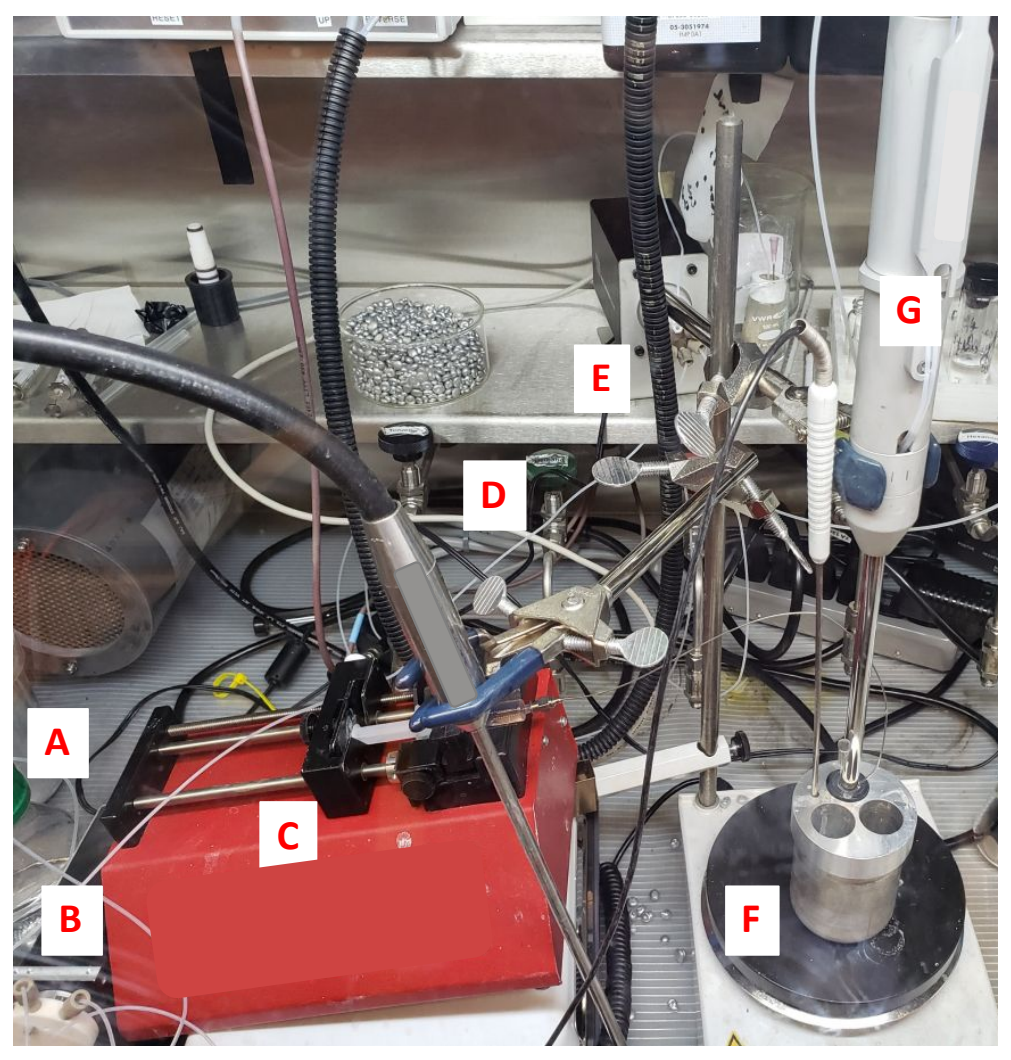

Figure S1: Labelled photo of the automated sampling device assembled in a glovebox. A) Solvent reservoir; B) Diluent pump; C) Syringe pump for dosing; D) Glovebox port for delivering samples to the HPLC; E) Rheodyne 6 port, 2 position valve; F) Hot plate / heat exchanger; G) Easysampler sampling probe. 


\section{Synthetic Procedures}<smiles>COc1ccc(N(c2ccccc2)c2ccc(OC)cc2)cc1</smiles>

\section{4-methoxy-N-(4-methoxyphenyl)- $N$-phenylaniline (4)}

To a 4 dram vial under a nitrogen atmosphere was added bis(4methoxyphenyl)amine (229 mg, $1.00 \mathrm{mmol})$, LiHMDS (251 mg, 1.50 $\mathrm{mmol})$, iodobenzene $(204 \mathrm{mg}, 1.00 \mathrm{mmol})$, THF $(8.4 \mathrm{~mL})$, and toluene $(300 \mu \mathrm{L})$ and the resultant solution was heated to $60{ }^{\circ} \mathrm{C}$. Palladium(II) acetate $(5.6 \mathrm{mg}, 25 \mu \mathrm{mol})$ and tri-tert-butylphosphine $(10.1 \mathrm{mg}, 50.0$ $\mu \mathrm{mol})$ in toluene $(200 \mu \mathrm{L})$ were mixed for 30 minutes for being added via syringe to initiate the reaction. A sampling sequence was then initiated.

ammonium chloride. The crude was extracted with ethyl acetate $(10 \mathrm{~mL}, 3 \mathrm{x})$. The organic extracts were washed with brine, dried $\left(\mathrm{Na}_{2} \mathrm{SO}_{4}\right)$, filtered, and concentrated under reduced pressure. The product was obtained after flash chromatography (95:5, petroleum ether / ethyl acetate) to afford a white solid (245 mg, $0.802 \mathrm{mmol}, 80 \%$ yield). Characterization data is consistent with that in the literature. ${ }^{3}$

'H NMR: $\left(400 \mathrm{MHz}, \mathrm{CDCl}_{3}\right) \delta 7.17(\mathrm{t}, \mathrm{J}=7.8 \mathrm{~Hz}, 2 \mathrm{H}), 7.05(\mathrm{~d}, \mathrm{~J}=8.8 \mathrm{~Hz}, 4 \mathrm{H}), 6.94(\mathrm{~d}, \mathrm{~J}=8.2$ $\mathrm{Hz}, 2 \mathrm{H}), 6.89-6.80(\mathrm{~m}, 5 \mathrm{H}), 3.80(\mathrm{~s}, 6 \mathrm{H})$.

${ }^{13} \mathrm{C}\left\{{ }^{1} \mathrm{H}\right\}$ NMR: $\left(101 \mathrm{MHz}, \mathrm{CDCl}_{3}\right) \delta 155.8,148.9,141.3,129.1,126.5,121.1,120.70,114.8,55.6$ MS ESI+: $\left(m / z\right.$ calc. for $\left.\mathrm{C}_{20} \mathrm{H}_{19} \mathrm{NO}_{2},[\mathrm{M}+\mathrm{H}]=306.2\right)$; found $=306.2$<smiles>COc1ccc(N(c2ccc(Br)cc2)c2ccc(OC)cc2)cc1</smiles>

\section{4-bromo-N,N-bis(4-methoxyphenyl)aniline (6)}

To a 4 dram vial under a nitrogen atmosphere was added bis(4methoxyphenyl)amine (229 mg, $1.00 \mathrm{mmol})$, LiHMDS (251 mg, 1.50 $\mathrm{mmol})$, 1-bromo-4-iodobenzene (283 mg, $1.00 \mathrm{mmol})$ THF $(8.4 \mathrm{~mL})$ and toluene $(300 \mu \mathrm{L})$ and the resulting solution was heated to $60{ }^{\circ} \mathrm{C}$. Palladium(II) acetate $(5.6 \mathrm{mg}, 25.0 \mu \mathrm{mol})$ and tri-tert-butylphosphine $(10.1 \mathrm{mg}, 50.0 \mu \mathrm{mol})$ in toluene $(200 \mu \mathrm{L})$ were mixed for 30 minutes for being added via syringe to initiate the reaction. After 30 hours the reaction was cooled to room temperature and quenched with saturated aqueous ammonium chloride. The crude was extracted with ethyl acetate $(10 \mathrm{~mL}, 3 \mathrm{x})$. The organic extracts were washed with brine, dried $\left(\mathrm{Na}_{2} \mathrm{SO}_{4}\right)$, filtered, and concentrated under reduced pressure. The crude residue was purified via flash chromatography (petroleum ether/ethyl acetate; 9:1) to afford 6 (62 $\mathrm{mg}, 0.16 \mathrm{mmol}, 16 \%$ yield) as a white solid. Characterization data is consistent with that in the literature. ${ }^{4}$

${ }^{1} \mathrm{H}$ NMR: $\left(400 \mathrm{MHz}, \mathrm{C}_{6} \mathrm{D}_{6}\right) \delta 7.20-7.16(\mathrm{~m}, 2 \mathrm{H}), 6.99-6.93(\mathrm{~m}, 4 \mathrm{H}), 6.80-6.72(\mathrm{~m}, 2 \mathrm{H}), 6.72$ $-6.65(\mathrm{~m}, 4 \mathrm{H}), 3.29(\mathrm{~s}, 6 \mathrm{H})$

${ }^{13} \mathrm{C}$ NMR: $\left(101 \mathrm{MHz}, \mathrm{C}_{6} \mathrm{D}_{6}\right) \delta 156.7,148.4,141.0,132.3,126.9,122.6,115.2,113.0,55.0$

MS ESI+: $m / z$ calc. for $\mathrm{C}_{20} \mathrm{H}_{18} \mathrm{BrNO}_{2}$, $[\mathrm{M}]^{+}=383.1$, found 383.0

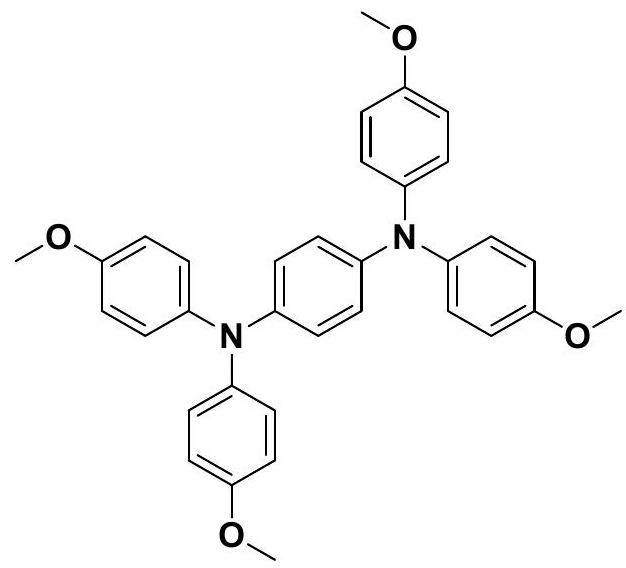

$N^{1}, N^{1}, N^{4}, N^{4}$-tetrakis(4-methoxyphenyl)benzene-1,4diamine (8) 
To a 4 dram vial under a nitrogen atmosphere was added bis(4-methoxyphenyl)amine (446 mg, $1.94 \mathrm{mmol}$ ), LiHMDS (444 mg, $2.65 \mathrm{mmol}$ ), 1-bromo-4-iodobenzene (250 mg, $0.88 \mathrm{mmol})$, THF $(8.4 \mathrm{~mL})$ and toluene $(300 \mu \mathrm{L})$ and the resulting solution was heated to $60{ }^{\circ} \mathrm{C}$. Palladium(II) acetate $(5.6 \mathrm{mg}, 25.0 \mu \mathrm{mol})$ and tri-tert-butylphosphine $(10.1 \mathrm{mg}, 50.0 \mu \mathrm{mol})$ in toluene $(200 \mu \mathrm{L})$ were mixed for 30 minutes for being added via syringe to initiate the reaction. After 30 hours the reaction was cooled to room temperature and quenched with saturated aqueous ammonium chloride. the crude was extracted with ethyl acetate $(10 \mathrm{~mL}, 3 \mathrm{x})$. The organic extracts were washed with brine, dried $\left(\mathrm{Na}_{2} \mathrm{SO}_{4}\right)$, filtered, and concentrated under reduced pressure. Methanol $(150 \mathrm{~mL})$ was added to the crude residue to precipitate out the product. The resulting heterogeneous solution was triturated via sonicator. The mixture was then vacuum filtered and the cake was washed with methanol followed by petroleum ether, then dried under vacuum to afford the purified product (310 $\mathrm{mg}, 0.58 \mathrm{mmol}, 66 \%)$ as a white solid. Characterization data is consistent with that in the literature. ${ }^{5}$

1H NMR: (400 MHz, $\left.\mathrm{C}_{6} \mathrm{D}_{6}\right) \delta 7.15-7.11$ (m, obscured by solvent signal), $7.07(\mathrm{~s}, 4 \mathrm{H}), 6.74-6.70$ $(\mathrm{m}, 8 \mathrm{H}), 3.29(\mathrm{~s}, 12 \mathrm{H})$

${ }^{13} \mathrm{C}\left\{{ }^{1} \mathrm{H}\right\}$ NMR: $\left(101 \mathrm{MHz}, \mathrm{C}_{6} \mathrm{D}_{6}\right) \delta 156.0,143.5,142.2,126.0,123.8,115.1,55.0$.

MS ESI+: $m / z$ calc. for $\mathrm{C}_{34} \mathrm{H}_{32} \mathrm{~N}_{2} \mathrm{O}_{4,}[\mathrm{M}]^{+}=532.1$, found 532.3 


\section{Reproducibility Tests}

\section{Calculating the Easysampler Pocket Volume}

Toluene $(10.0 \mathrm{~mL})$ was added to a sealed vial inside of the nitrogen filled glovebox. The Easysampler was then introduced into the vial through a hole in the Teflon screw cap. The default sampling method was used to collect a total of 50 samples. The toluene peak response $(254 \mathrm{~nm})$ was plotted as a function of injection number.
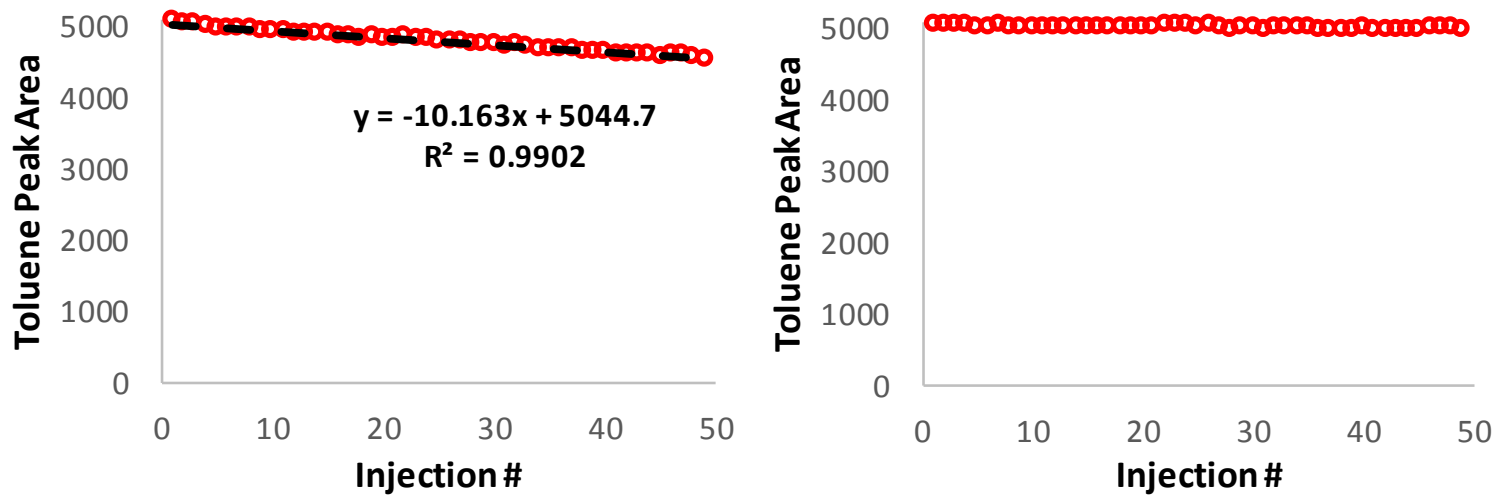

Figure S2: Relationship between toluene peak area and injection number when $10.0 \mathrm{~mL}$ of toluene is analyzed using automated sampling platform 50 times. Negative trend correlates to the dilution (THF) observed from each sample (left). Same relationship after applying dilution factor correction (Eq S1)

$$
E q S 1=\frac{\text { Peak Area }\left(V_{0}+\operatorname{Inj} \#(0.02015 m L)\right.}{V_{0}}
$$




\section{Determining Relationship Between Diluent Volume and Detector Response}

Toluene $(20.0 \mathrm{~mL})$ was added to a sealed vial inside of the nitrogen filled glovebox. The Easysampler was then introduced into the vial through a hole in the Teflon screw cap. The default sampling method was to collect a sample in triplicate with the following diluent volumes: $400,500,600,650,700,750,800,850,900,1000,1200 \mu \mathrm{L}$. The average peak area of each triplicate series was plotted against the diluent volume, error bars are \pm one standard deviation of the series.

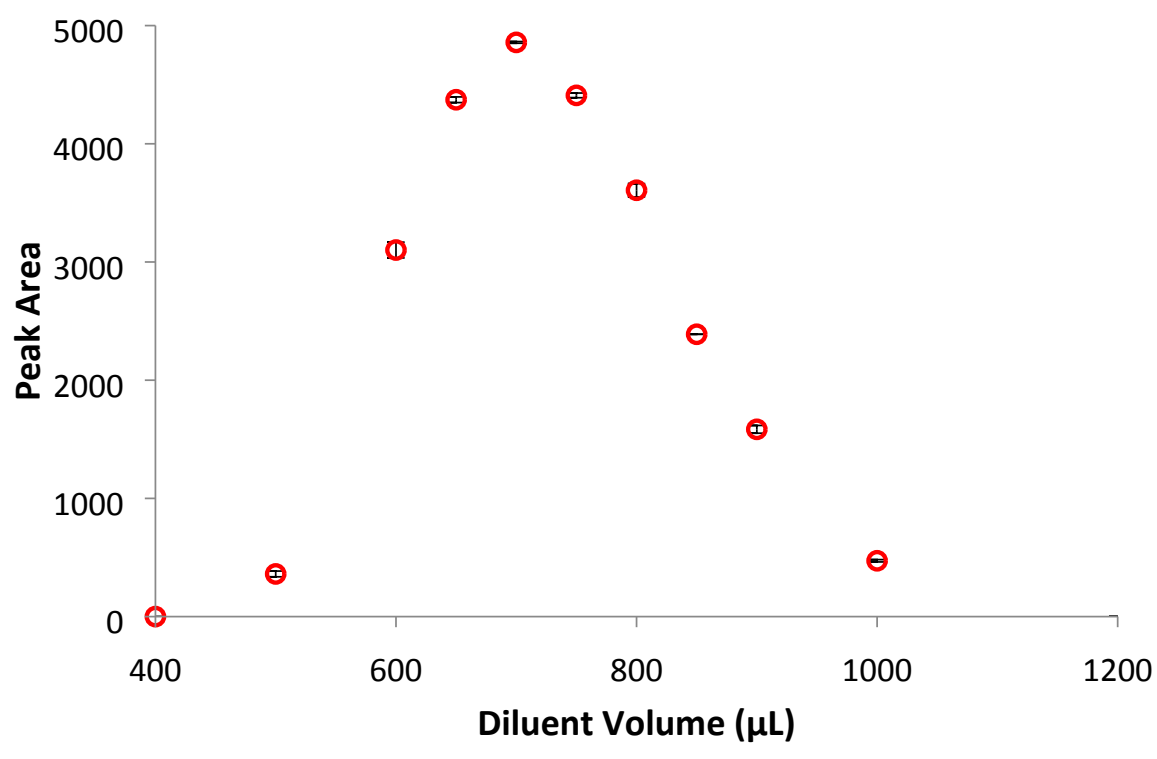

Figure S3: Relationship between diluent volume and detector response when a vial of toluene is sampled from within a glovebox. Each data point represents the average of a triplicate series. Error bars represent \pm one standard deviation of the series. 


\section{Reaction Monitoring Data \\ Coupling lodobenzene}

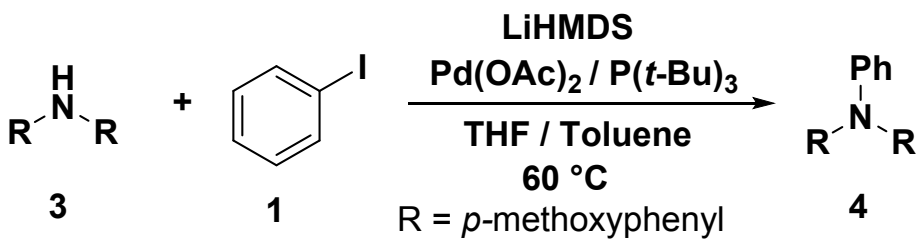

To a 4 dram vial under a nitrogen atmosphere was added bis(4-methoxyphenyl)amine (229 mg, $1.00 \mathrm{mmol})$, LiHMDS (251 mg, $1.50 \mathrm{mmol})$, iodobenzene $(204 \mathrm{mg}, 1.00 \mathrm{mmol})$ THF $(8.4 \mathrm{~mL})$ and toluene $(300 \mu \mathrm{L})$. The stirred solution was heated at $60{ }^{\circ} \mathrm{C}$. Palladium(II) acetate $(5.6 \mathrm{mg}$, $25 \mu \mathrm{mol})$ and tri-tert-butylphosphine $(10.1 \mathrm{mg}, 50.0 \mu \mathrm{mol})$ dissolved in toluene $(200 \mu \mathrm{L})$ were mixed for 30 minutes before beinginjected via syringe to initiate and a sampling sequence was then begun. A diluent volume of $700 \mu \mathrm{L}$ was used to deliver the reaction aliquot $(1.0 \mathrm{~mL} / \mathrm{min})$ to the injection valve. Samples were analyzed using the general HPLC method.

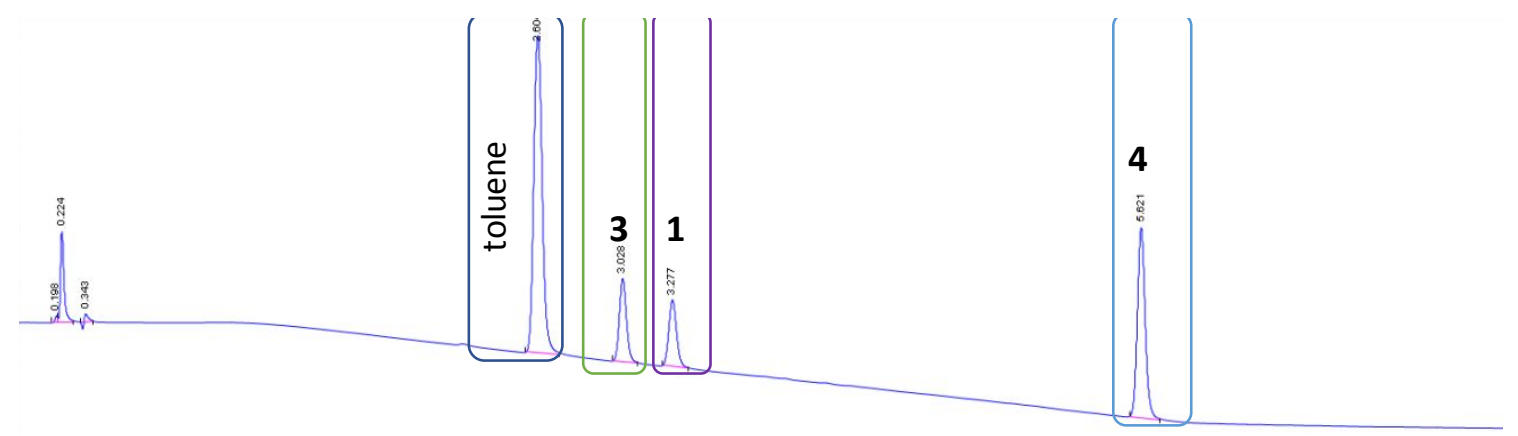

Figure S4: Sample HPLC chromatogram during a monitored Buchwald-Hartwig reaction coupling 1 and 3 to form 4 .

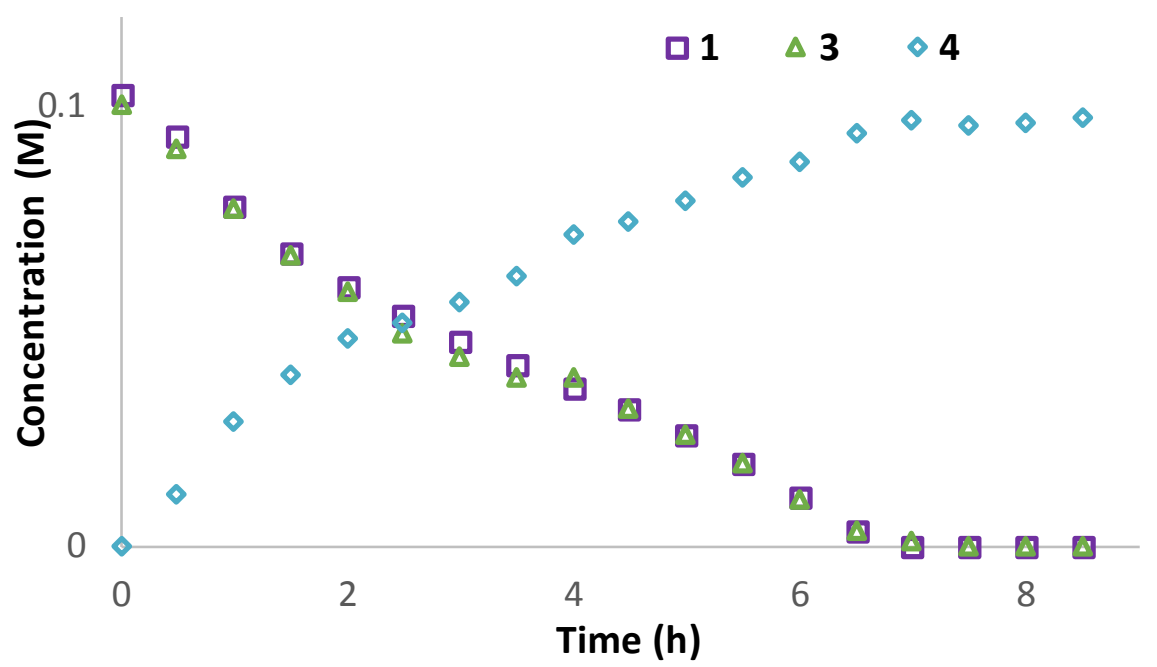

Figure S5: Reaction time-course data for the Buchwald/Hartwig amination coupling 1 and $\mathbf{3}$ to form 4. Sample aliquots were collected using the automated sampling platform and analyzed using online HPLC. 


\section{Coupling Bromobenzene}

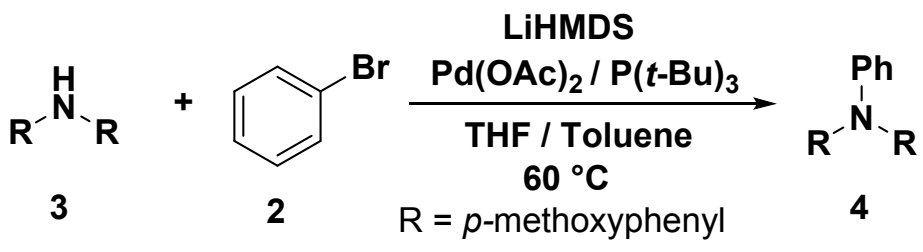

To a 4 dram vial under a nitrogen atmosphere was added bis(4-methoxyphenyl)amine (229 mg, $1.00 \mathrm{mmol})$, LiHMDS (251 mg, $1.50 \mathrm{mmol})$, bromobenzene $(157 \mathrm{mg}, 1.00 \mathrm{mmol})$ THF $(8.4 \mathrm{~mL})$ and toluene $(300 \mu \mathrm{L})$. The stirred solution was heated at $60{ }^{\circ} \mathrm{C}$. Palladium(II) acetate $(5.6 \mathrm{mg}, 25$ $\mu \mathrm{mol})$ and tri-tert-butylphosphine $(10.1 \mathrm{mg}, 50.0 \mu \mathrm{mol})$ dissolved in toluene $(200 \mu \mathrm{L})$ were mixed for 30 minutes before being injected via syringe to initiate the reaction and a sampling sequence was then begun. A diluent volume of $700 \mu \mathrm{L}$ was used to deliver the reaction aliquot $(1.0 \mathrm{~mL} /$ min) onto the injection valve. Samples were analyzed using the general HPLC method.

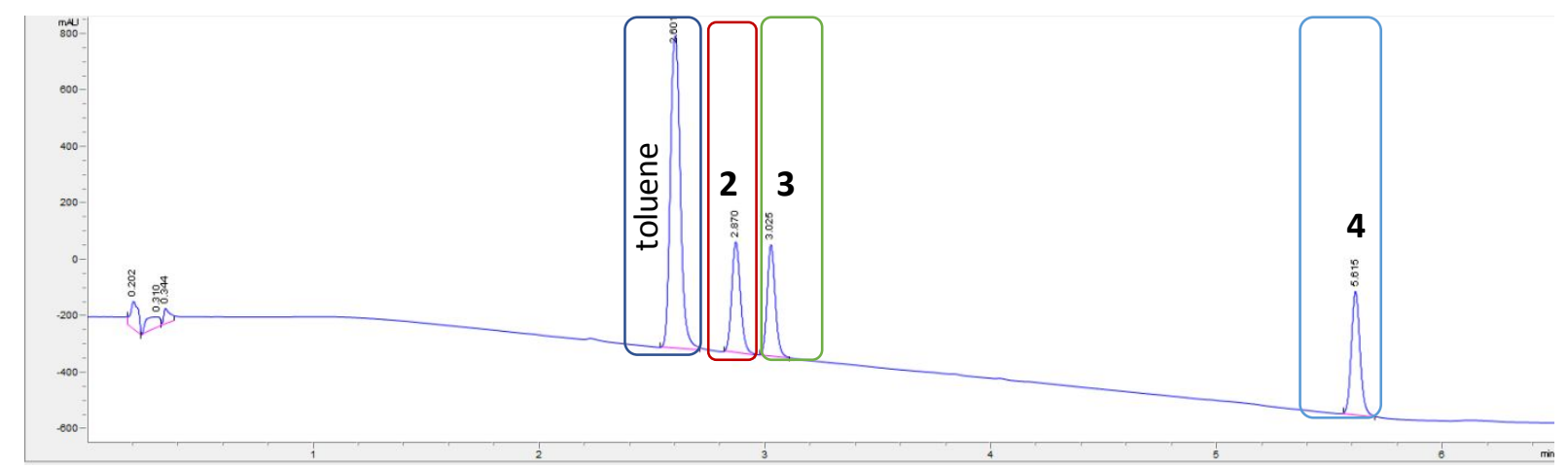

Figure S6: Sample HPLC chromatogram during a monitored Buchwald/Hartwig reaction coupling 2 and 3 to form 4 .

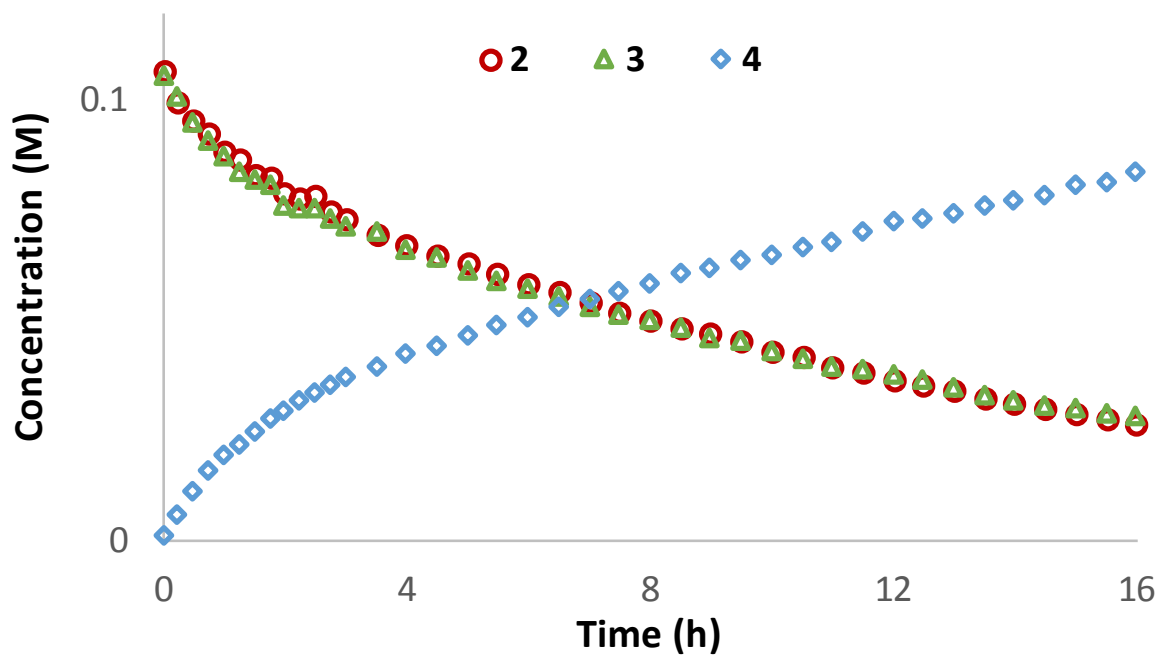

Figure S7: Reaction time-course data for the Buchwald/Hartwig amination coupling 2 and 3 to form 4. Sample aliquots were collected using the automated sampling platform and analyzed using online HPLC. 


\section{Competition Reaction Coupling Bromobenzene and lodobenzene}

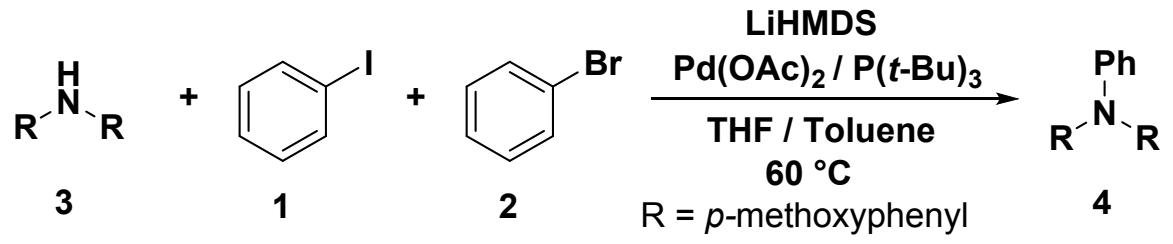

To a 4 dram vial under a nitrogen atmosphere was added bis(4-methoxyphenyl)amine (229 mg, $1.00 \mathrm{mmol})$, LiHMDS (251 $\mathrm{mg}, 1.50 \mathrm{mmol})$, bromobenzene $(79 \mathrm{mg}, 0.50 \mathrm{mmol})$, iodobenzene $(102 \mathrm{mg}, 0.50 \mathrm{mmol})$ THF $(8.4 \mathrm{~mL})$ and toluene $(300 \mu \mathrm{L})$. The stirred solution was heated at 60 ${ }^{\circ} \mathrm{C}$. Palladium(II) acetate $(5.6 \mathrm{mg}, 25 \mu \mathrm{mol})$ and tri-tert-butylphosphine $(10.1 \mathrm{mg}, 1.23 \mathrm{molar}, 0.05$ $\mathrm{Eq}, 50.0 \mu \mathrm{mol})$ dissolved in toluene $(200 \mu \mathrm{L})$ were mixed for 30 minutes before being injected via syringe to initiate the reaction and a sampling sequence was then initiated. A diluent volume of $700 \mu \mathrm{L}$ was used to deliver the reaction aliquot $(1.0 \mathrm{~mL} / \mathrm{min})$ onto the injection valve. Samples were analyzed using the general HPLC method.

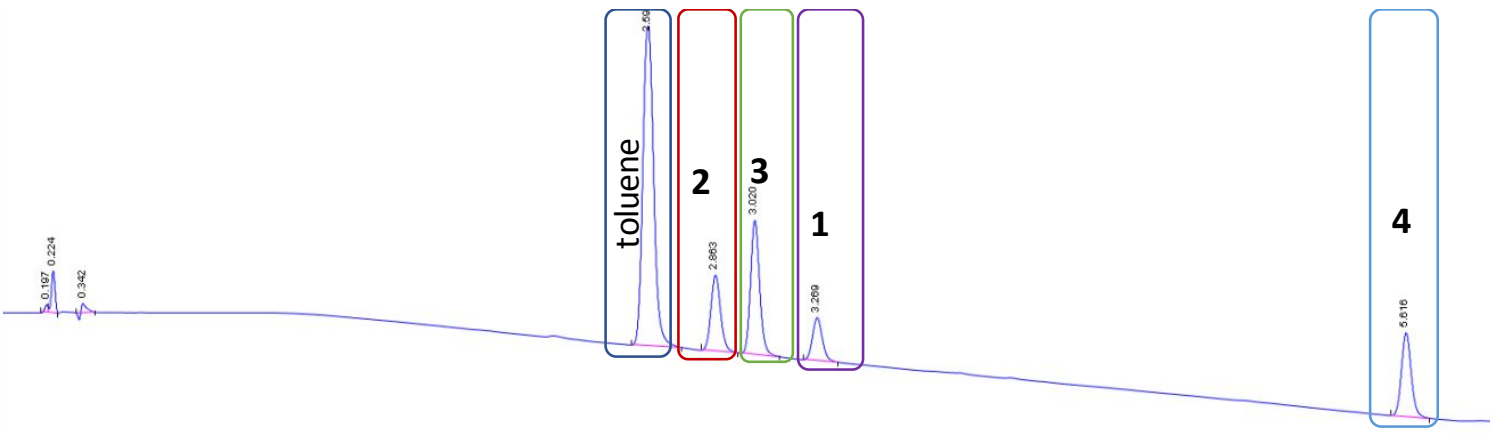

Figure S8: Sample HPLC chromatogram during a monitored Buchwald/Hartwig competition reaction coupling 1 with 2 and 3 to form 4 .

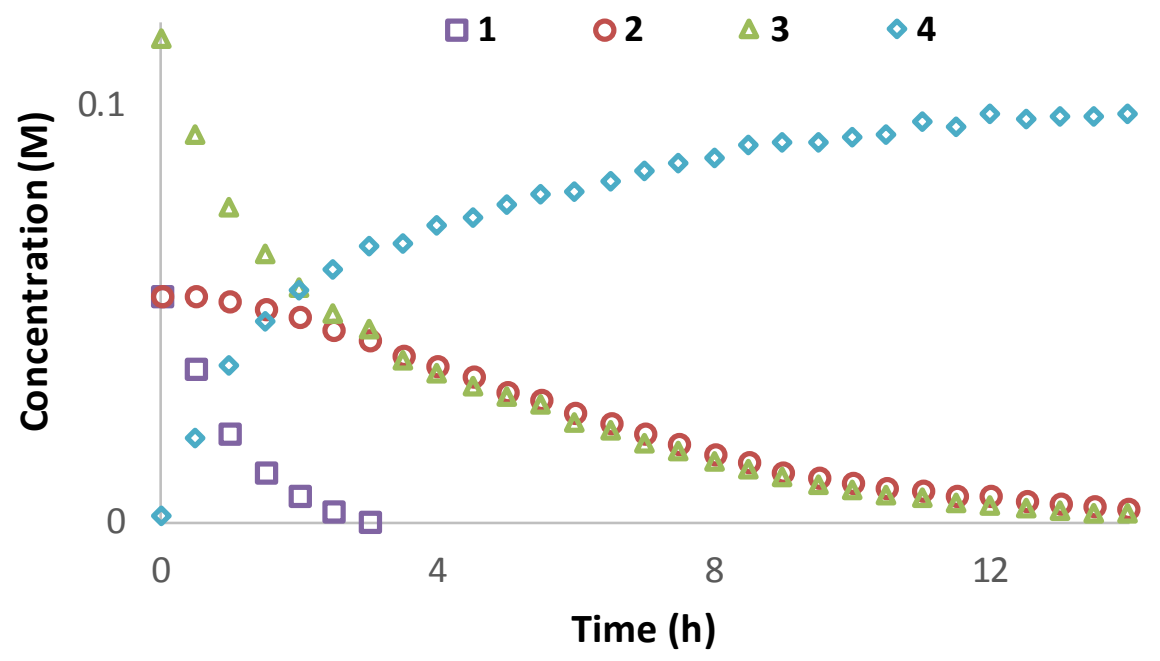

Figure S9: Reaction time-course data for the competition Buchwald/Hartwig amination coupling 1 with 2 and 3 to form 4 . Sample aliquots were collected using the automated sampling platform and analyzed using online HPLC. 


\section{Coupling 1-bromo-4-iodobenzene}

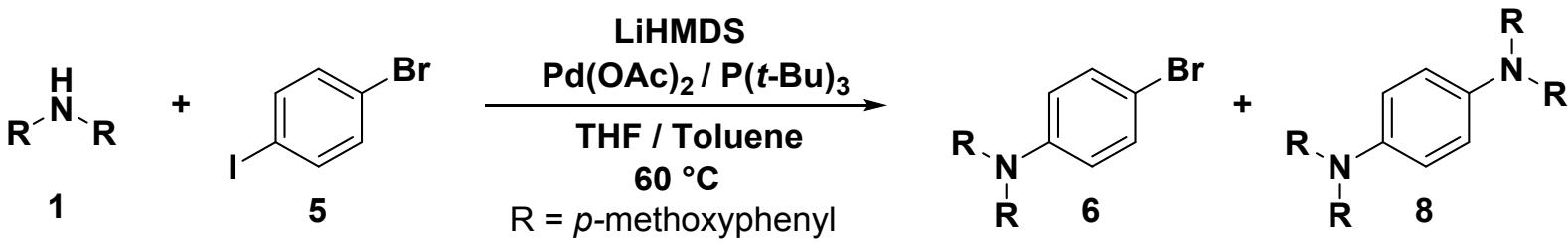

To a 4 dram vial under a nitrogen atmosphere was added bis(4-methoxyphenyl)amine (229 mg, $1.00 \mathrm{mmol}$ ), LiHMDS (251 mg, $1.50 \mathrm{mmol}$ ), 1-bromo-4-iodobenzene (283 mg, $1.00 \mathrm{mmol}$ ) THF $(8.4 \mathrm{~mL})$ and toluene $(300 \mu \mathrm{L})$. The stirred solution was heated at $60{ }^{\circ} \mathrm{C}$. Palladium(II) acetate $(5.6 \mathrm{mg}, 25 \mu \mathrm{mol})$ and tri-tert-butylphosphine $(10.1 \mathrm{mg}, 1.23 \mathrm{molar}, 0.05 \mathrm{Eq}, 50.0 \mu \mathrm{mol})$ dissolved in toluene $(200 \mu \mathrm{L})$ were mixed for 30 minutes before being injected via syringe to initiate the reaction and a sampling sequence was then initiated. A diluent volume of $700 \mu \mathrm{L}$ was used to deliver the reaction aliquot $(1.0 \mathrm{~mL} / \mathrm{min})$ onto the injection valve. Samples were analyzed using the general HPLC sampling method.

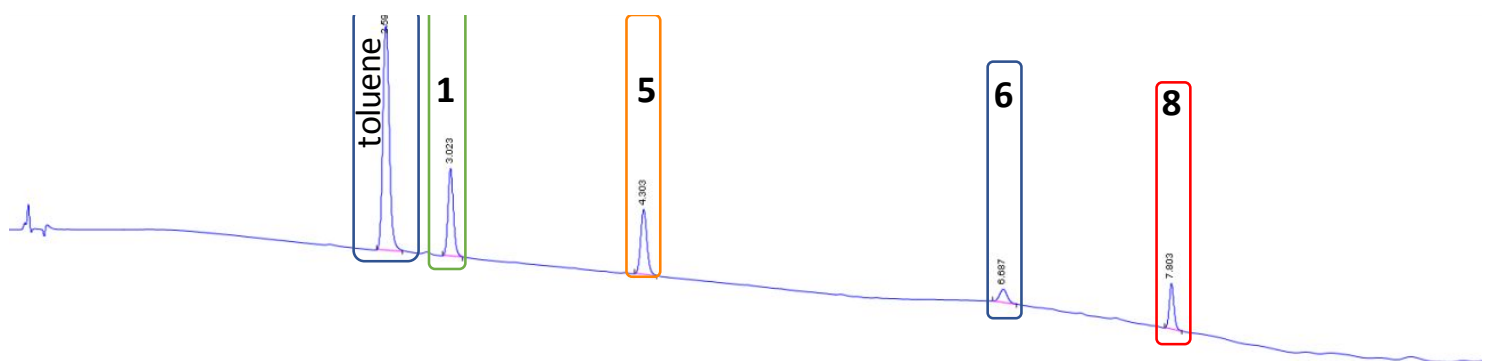

Figure S10: Sample HPLC chromatogram during a monitored Buchwald/Hartwig competition reaction coupling 1 with 5 to form 6 and 8 .

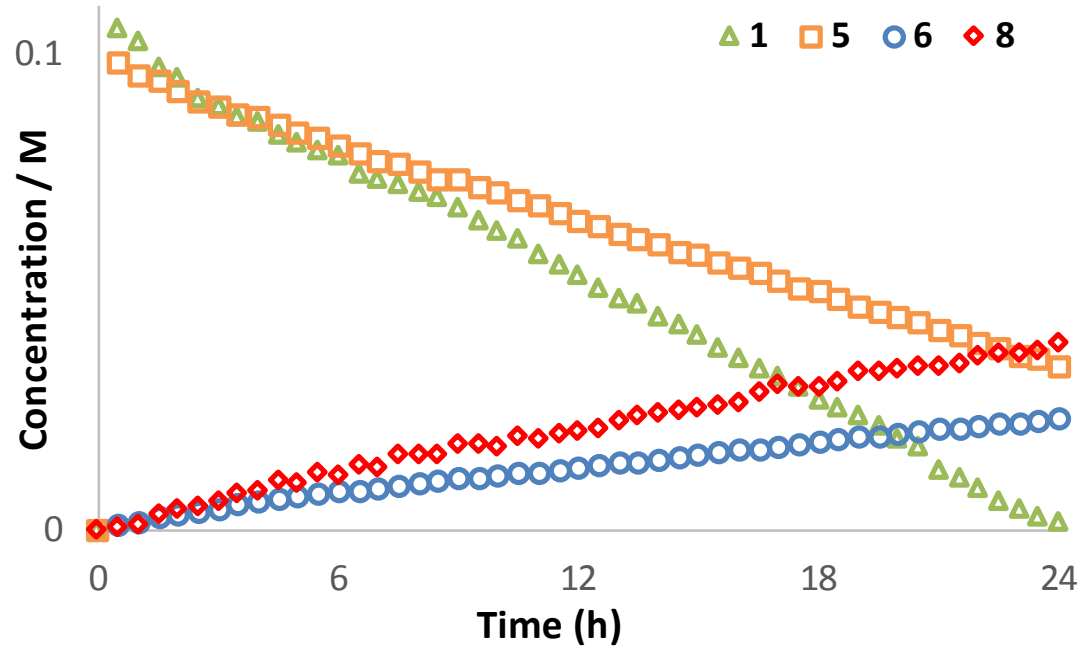

Figure S11: Reaction time-course data for the competition Buchwald/Hartwig amination coupling $\mathbf{1}$ with $\mathbf{5}$ to form $\mathbf{6}$ and $\mathbf{8}$. Sample aliquots were collected using the automated sampling platform and analyzed using online HPLC. 


\section{Calibration Curves}<smiles>Ic1ccccc1</smiles>

1<smiles>Brc1ccccc1</smiles>

2<smiles>[R]N[R]</smiles><smiles>[R20]c1ccccc1</smiles>

4<smiles>Brc1ccc(I)cc1</smiles>

5<smiles>[R20]c1ccc(Br)cc1</smiles>

6<smiles>[R20]Nc1ccc(N([R2])[R])cc1</smiles>

8

$\mathrm{R}=p$-methoxyphenyl

A stock solution (5.00 $\mathrm{mL}$ ) of each compound being calibrated ( $\mathbf{1}-\mathbf{5}$ and $\mathbf{8}$ ) was created by dissolving a known mass of material in THF/toluene (19:1). This stock solution was then sampled three times using the Easysampler sampling method. Peak areas were normalized by dividing by the toluene (internal standard) peak. The stock solution $(2.5 \mathrm{~mL})$ was then diluted into THF/toluene (19:1, $2.5 \mathrm{~mL}$ ) and the resultant diluted stock solution was sampled and quantified again three times. This diluting and sampling protocol was repeated an additional two times to collect a total of four data points in triplicate. HPLC calibration curve data was used to calculate the [6] based using the following assumption:

$[6]_{\mathrm{t}}=[5]_{0}-[5]_{\mathrm{t}}-[8]_{\mathrm{t}}$

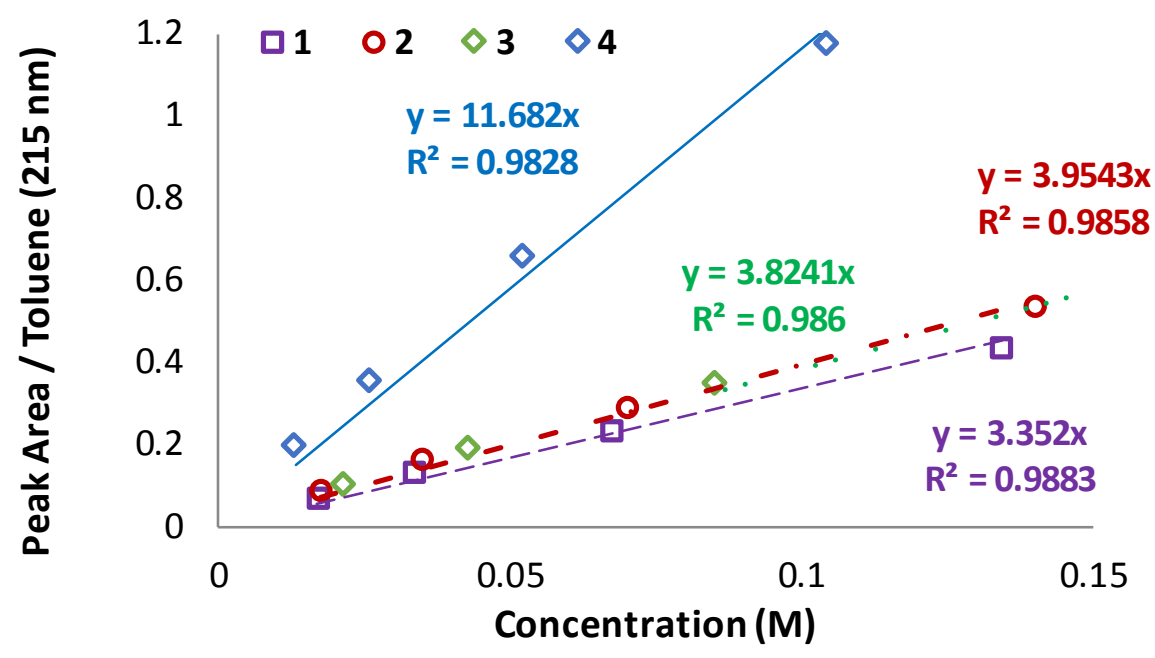

Figure S12: HPLC Calibration curves to allow for quantification of 1, 2, 3, and 4 directly from normalized peak area. Integration of all UV peaks completed at a wavelength of $215 \mathrm{~nm}$. 


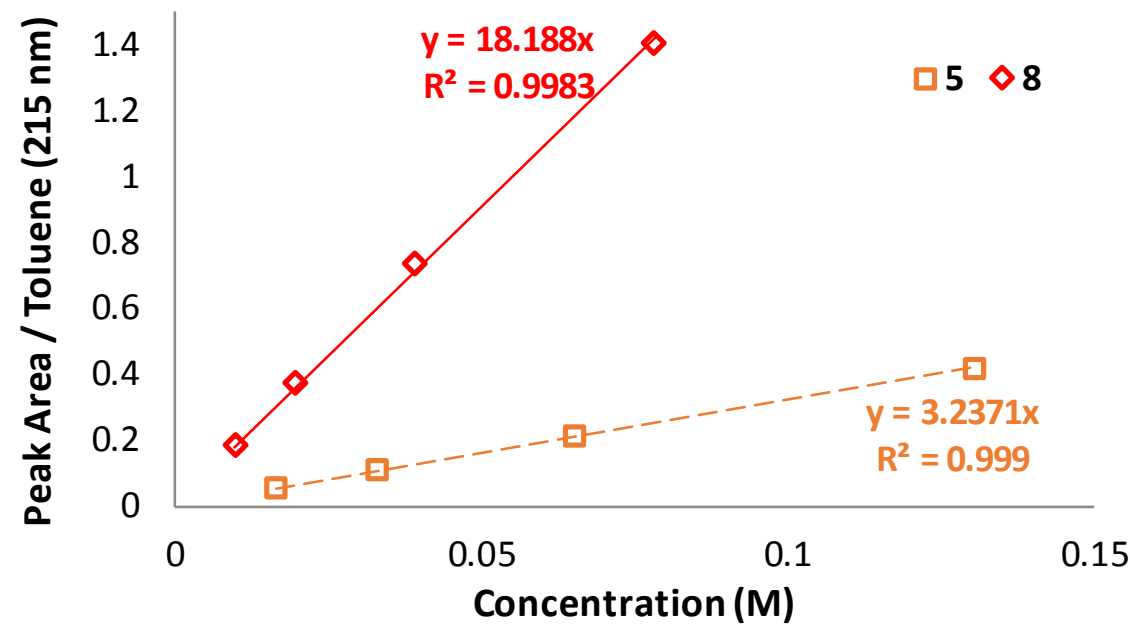

Figure S13: HPLC Calibration curves to allow for quantification of $\mathbf{5}$ and $\mathbf{8}$ directly from normalized peak area. Integration of all UV peaks completed at a wavelength of $215 \mathrm{~nm}$. 


\section{Copasi Modeling}

\section{Early Models}

The following models were created in COPASI to approximate kinetic behaviour before experimentation.

1)

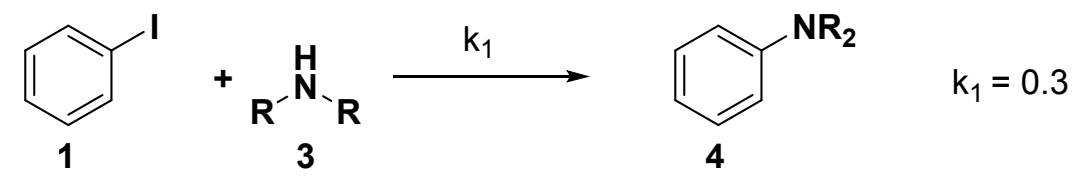

2)

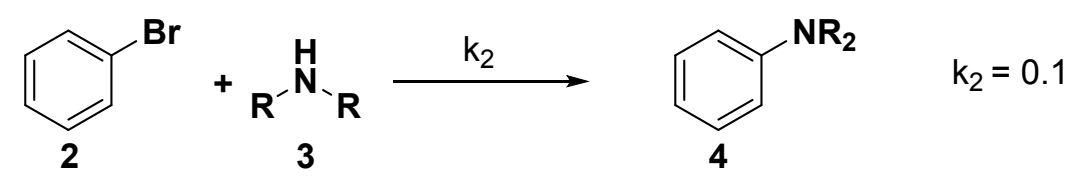

3)
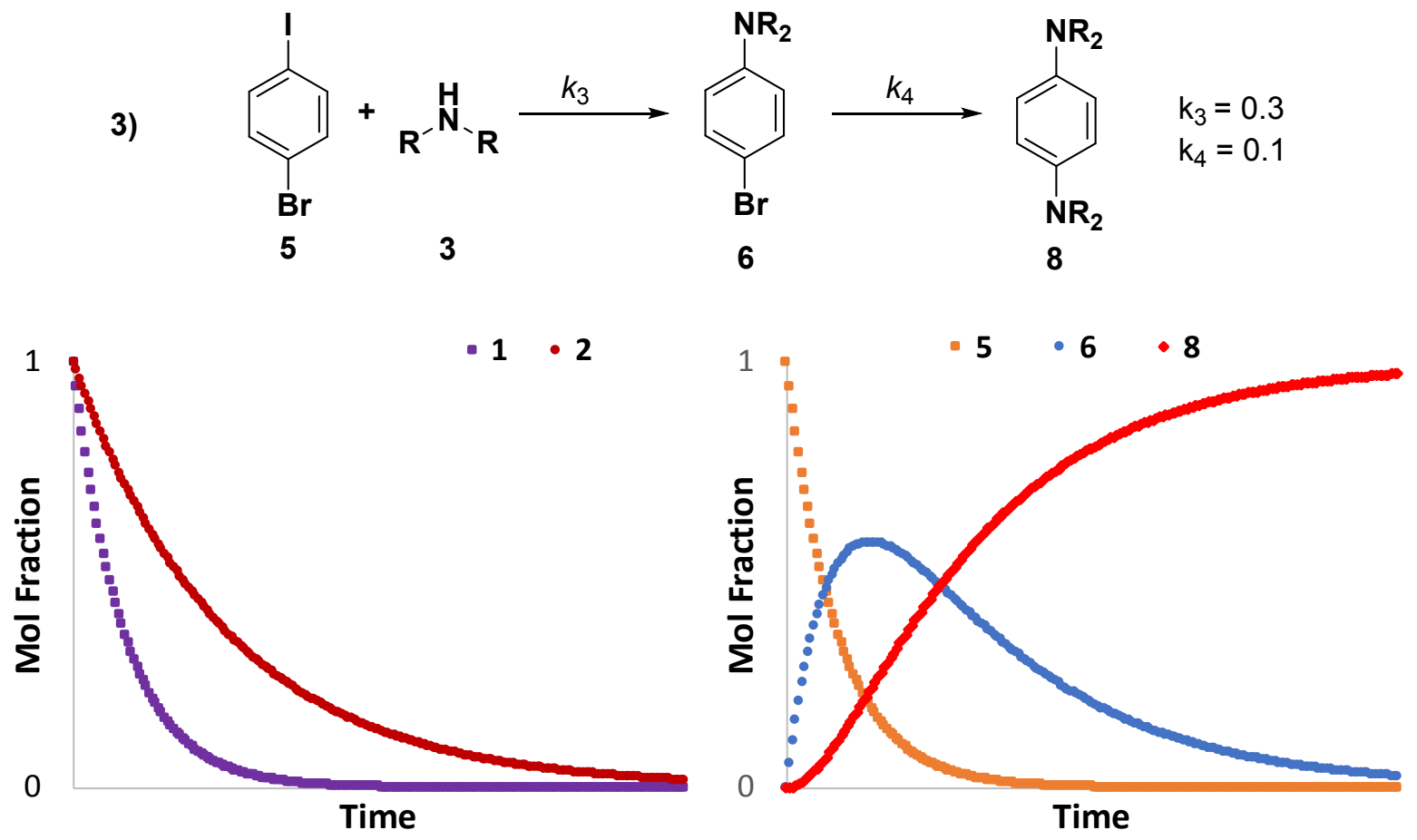

Figure S14: COPASI model for reactions 1) and 2) in competition and in parallel (left). COPASI model for the cascade reaction 3) using substrate 5. 


\section{Updated Competition Reaction Model}

$$
\begin{aligned}
& \operatorname{Pd}(\mathrm{OAc})_{2}+2 \mathrm{~L} \stackrel{k_{1}}{\longrightarrow} \mathrm{PdL}+\mathrm{POOAc} \quad \mathrm{k}_{1}=1.0 \times 10^{8} \\
& P d L+\frac{k_{2}}{k_{-2}} \underset{L-P d^{\prime \prime}-I}{P h}
\end{aligned}
$$

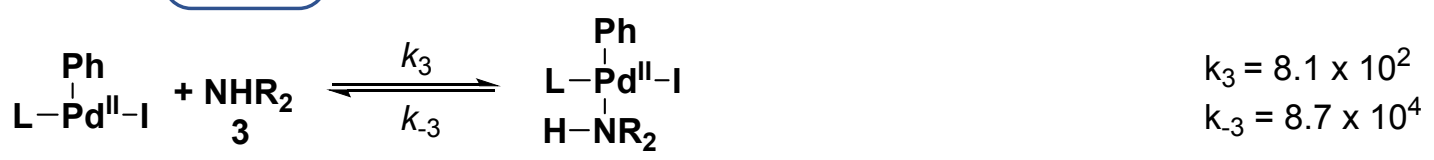

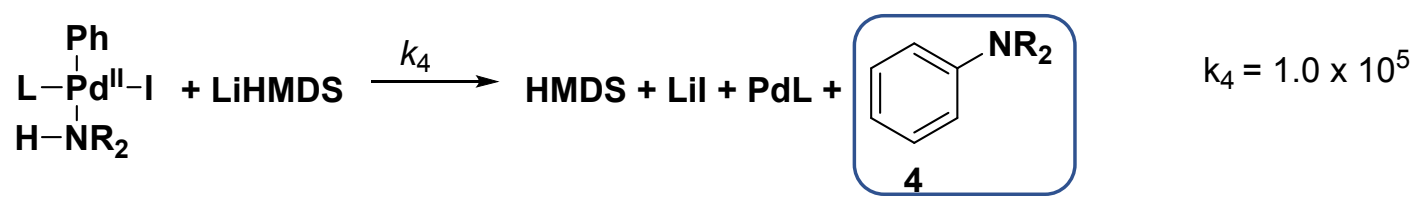

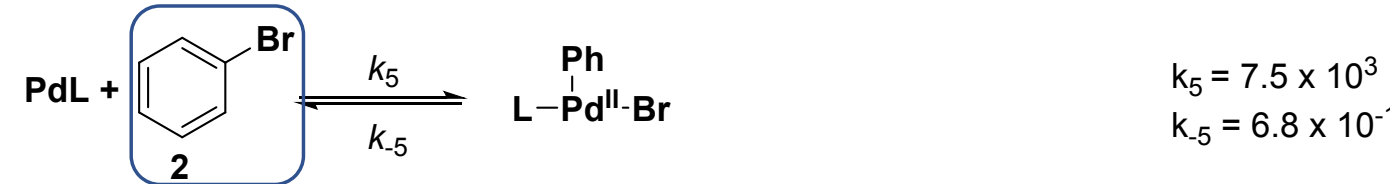

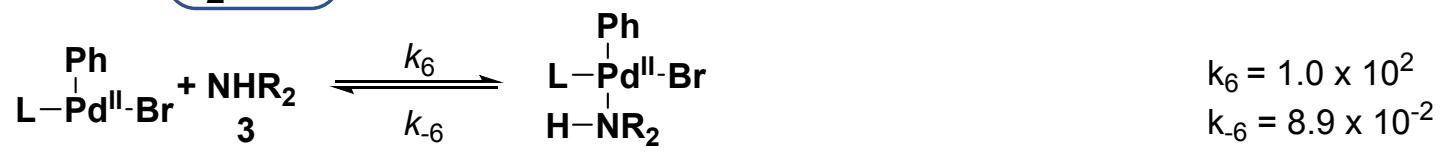

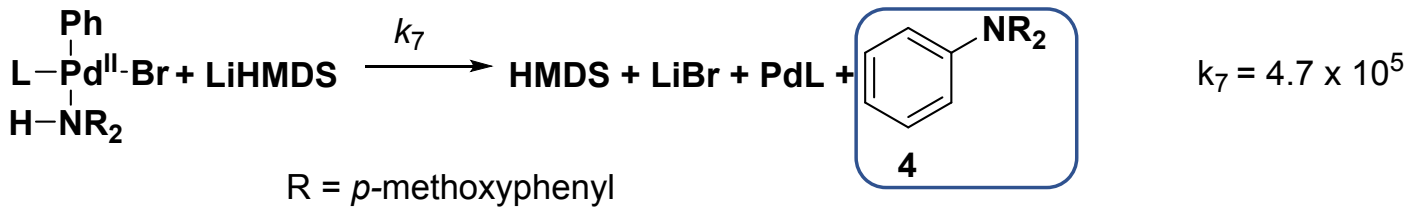

Listed rate constants were generated through the parameter estimation workflow in COPASI, where the time-course concentrations of materials 1, 2, 3, and 4 were fit using an evolutionary programming method with a population size of 20 and 200000 generations.

Input experimental data was obtained from three independent reactions, where the initial concentrations of the starting materials were adjusted. The parameter fit is attempting to recapitulate the concentration vs time profile for the observed starting materials, intermediates or products. The three time-course data sets correspond to:

1) Isolated reaction with iodobenzene (1) (bromobenze is absent)

2) Isolated reaction with bromobenzene (2) (iodobenzene is absent)

3 ) Competition reaction between iodo-and bromobenzene. (1 and 2) 
In the model above, compounds for which analytical data has been obtained are highlighted (box). However, as we have no concentration data for the intermediates, their relative concentration and estimated rate constants associated with these species are not unique and subject to wide variation.

Using this technique to interrogate the competition data allows the researcher to confidently address questions about the relative magnitude of certain rate constants, but not their absolute value. Our confidence in conclusions drawn from this method come from repetition of computational simulations and evaluation of the optimized parameters from multiple calculations. Tabulated below we show the results from 10 parallel optimizations.

\begin{tabular}{|c|c|c|c|c|c|c|c|c|c|c|}
\hline & 1 & 2 & 3 & 4 & 5 & 6 & 7 & 8 & 9 & 10 \\
\hline k1 & 99999957 & 7999996.56 & 12999994.4 & 90999960.9 & 80999965.2 & 93999959.6 & 88999961.7 & 93999959.6 & 8999996.13 & 90999960.9 \\
\hline k2 & 99994666 & 9999466.6 & 95994879.4 & 22998773.2 & 19998933.2 & 6999626.62 & 84995466.1 & 64996532.9 & 22998773.2 & 999946.66 \\
\hline$k-2$ & $1.4587 \mathrm{E}-07$ & $3.0632 E-08$ & $1.4295 \mathrm{E}-07$ & $7.731 \mathrm{E}-08$ & $1.0648 \mathrm{E}-07$ & 5.3971E-08 & $3.5008 \mathrm{E}-08$ & $1.4003 \mathrm{E}-07$ & 2.9174E-09 & $4.376 \mathrm{E}-08$ \\
\hline k3 & 106.52 & 87.3464 & 38.3472 & 3.1956 & 75.6292 & 86.2812 & 77.7596 & 44.7384 & 4.2608 & 66.0424 \\
\hline$k-3$ & 0.005199 & 0.00187164 & 0.00270348 & 0.00353532 & 0.00025995 & 0.00244353 & 0.00265149 & 0.00213159 & 0.00041592 & 0.00187164 \\
\hline k4 & 994851.786 & 795881.428 & 596911.071 & 338249.607 & 935160.678 & 875469.571 & 935160.678 & 179073.321 & 895366.607 & 208918.875 \\
\hline k5 & 43898.54 & 11852.6058 & 32045.9342 & 4828.8394 & 8340.7226 & 17559.416 & 16242.4598 & 10974.635 & 12730.5766 & 438.9854 \\
\hline$k-5$ & $1.5707 \mathrm{E}-06$ & $1.1623 \mathrm{E}-06$ & 3.1414E-07 & $9.5813 \mathrm{E}-07$ & $1.2409 \mathrm{E}-06$ & $1.2409 \mathrm{E}-06$ & $8.6389 \mathrm{E}-07$ & $1.2566 \mathrm{E}-07$ & $1.5393 \mathrm{E}-06$ & $1.021 \mathrm{E}-06$ \\
\hline k6 & 40.5566 & 2.838962 & 2.838962 & 20.683866 & 30.41745 & 13.789244 & 32.039714 & 4.866792 & 19.467168 & 17.844904 \\
\hline$k-6$ & 0.0146 & 0.013286 & 0.006862 & 0.008906 & 0.002482 & 0.012556 & 0.007446 & 0.003358 & 0.001314 & 0.005694 \\
\hline k7 & 975189.557 & 263301.18 & 146278.434 & 887422.497 & 458339.092 & 526602.361 & 828911.123 & 877670.601 & 585113.734 & 897174.392 \\
\hline
\end{tabular}

This method reveals that some rate constants must adopt certain relative magnitudes in order for good agreement to be realized, particularly with cases such as this CN coupling where we fit three data sets with very unique reaction profiles. In particular we can see that:

1) Catalyst activation $\left(k_{1}\right)$ must be large indicating that activation is fast under these conditions or that we are starting from a well activation catalyst (no further activation is occurring on the timescale of the reaction).

2) Monopoly arises from a large difference in the rate constant for oxidative addition between $\mathrm{Ar}-\mathrm{I}\left(\mathrm{k}_{2}\right)$ and $\mathrm{Ar}-\mathrm{Br}\left(\mathrm{k}_{5}\right)$ - where $\mathrm{k}_{2}$ must always be larger than $\mathrm{k}_{5}$

3) While the oxidative addition appears to determine the catalyst selectivity, one of the following steps (amine coordination or reductive elimination) is likely turnover limiting

Thus, the absolute values of the listed constants are not unique, but rather reflect the relative magnitudes of the rate constants in the elementary steps. Individual comparison of experimental (marks) and fitted (line) data are displayed below. 


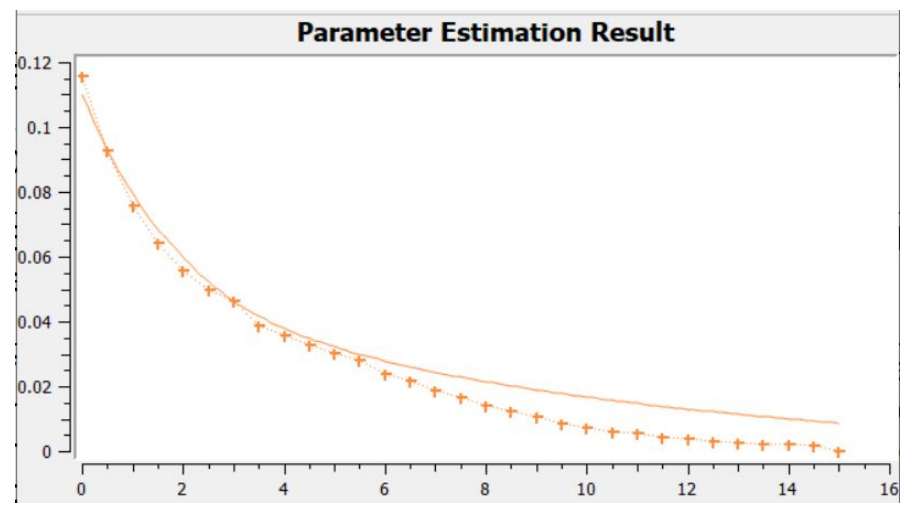

Figure S15: Comparison of experimental (crosses) and fitted (line) consumption profiles of 3 throughout the competition reaction.

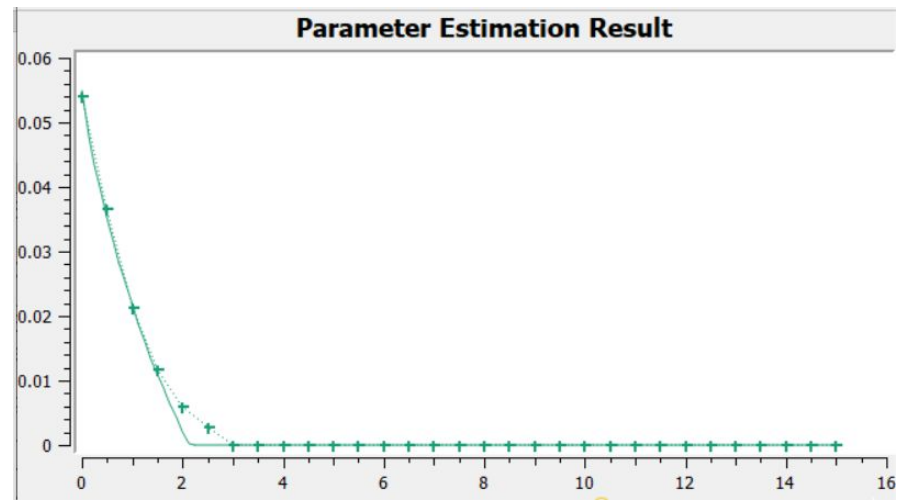

Figure S16: Comparison of experimental (crosses) and fitted (line) consumption profiles of 1 throughout the competition reaction.

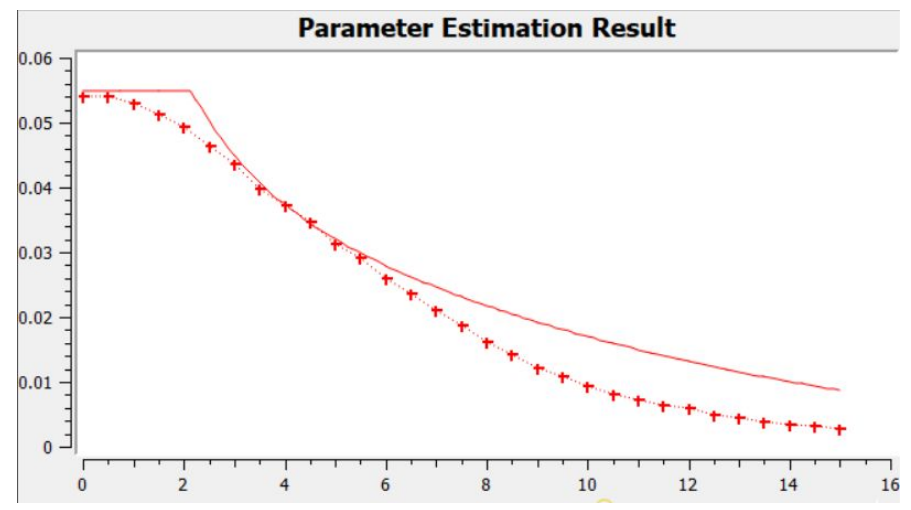

Figure S17: Comparison of experimental (crosses) and fitted (line) consumption profiles of 2 throughout the competition reaction.. 


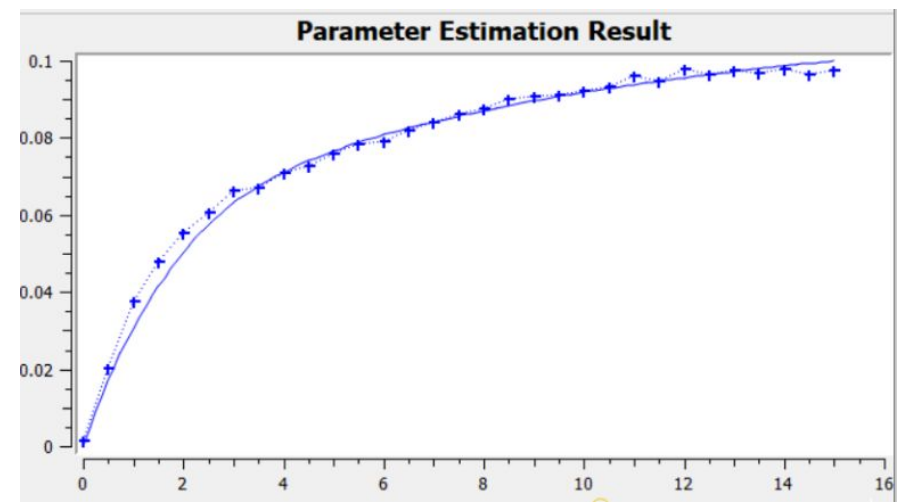

Figure S18: Comparison of experimental (crosses) and fitted (line) formation profiles of 4 throughout the competition reaction. 


\section{Updated Cascade Linear Reaction Model}

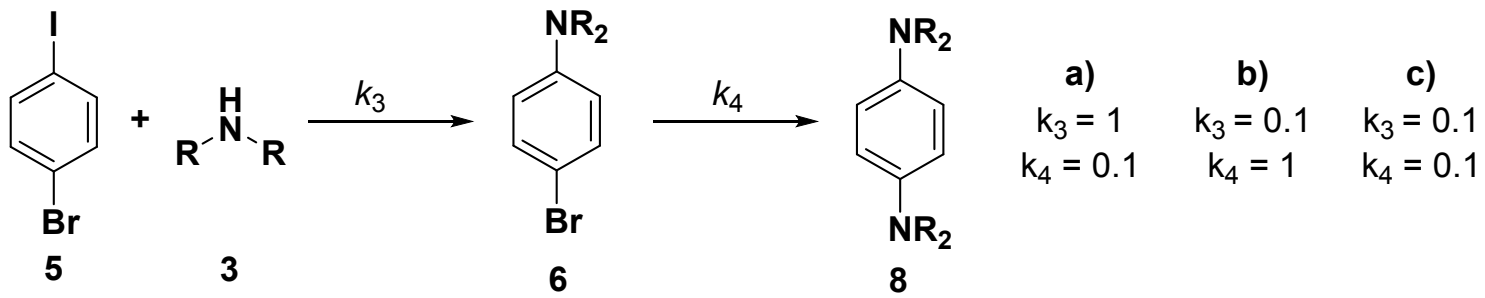
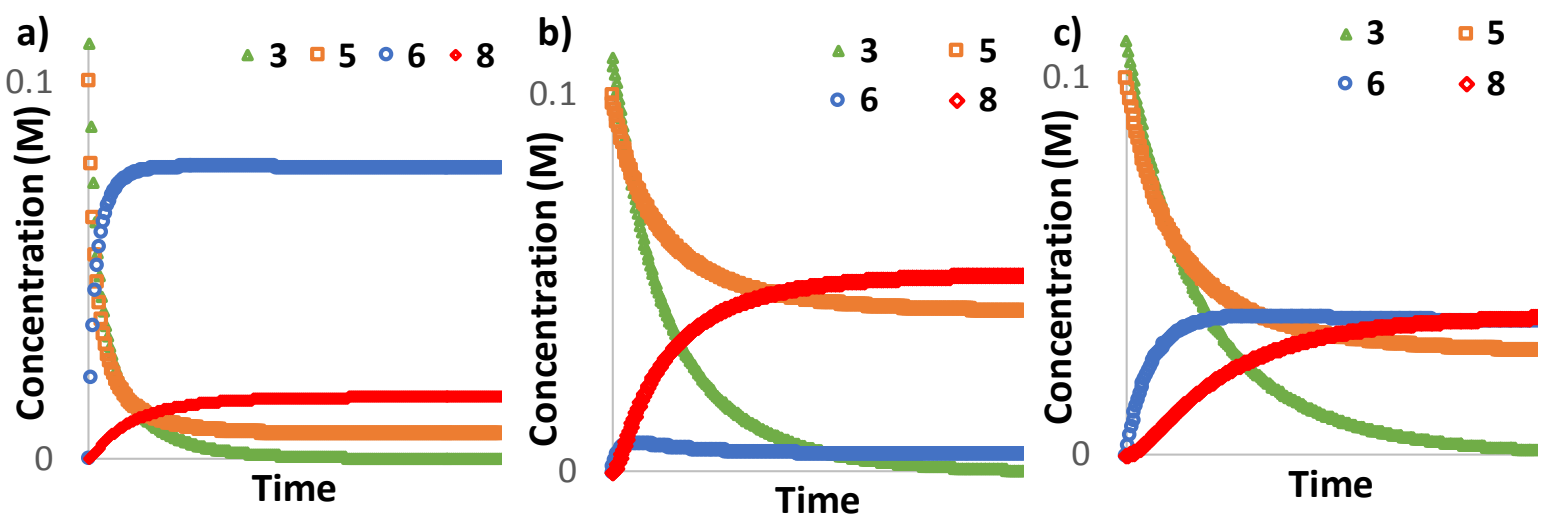

Figure S19: Updated cascade reaction COPASI model assuming a linear mechanism. Updated Cascade Ring-Walking Model

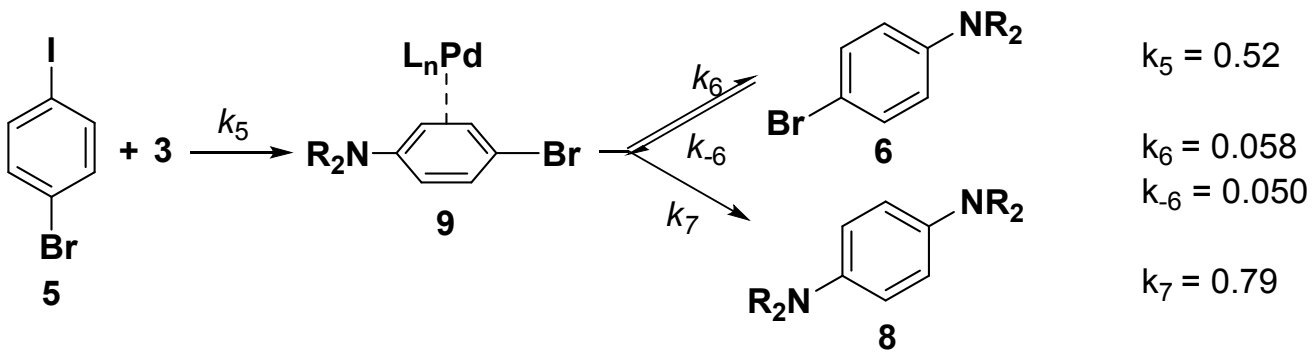

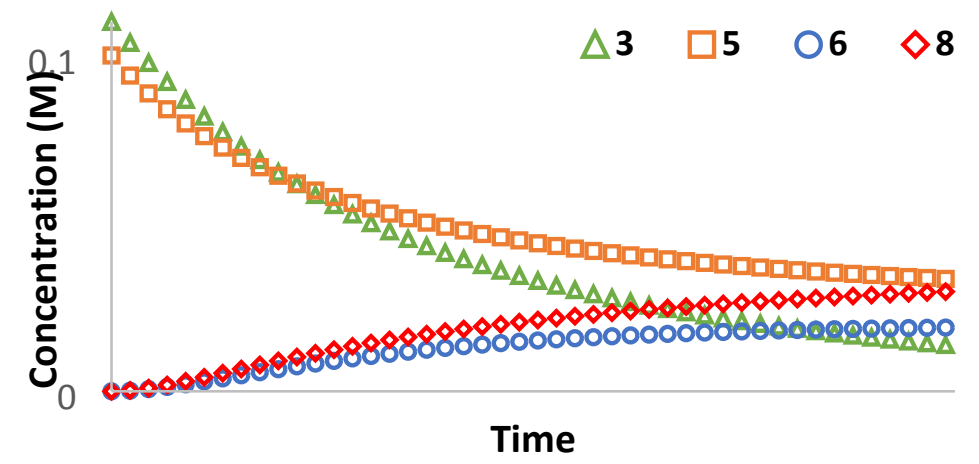

Figure S20: Updated COPASI model for the cascade reaction assuming a ring-walking mechanism. 


\section{References}

(1) Fulmer, G. R.; Miller, A. J. M.; Sherden, N. H.; Gottlieb, H. E.; Nudelman, A.; Stoltz, B. M.; Bercaw, J. E.; Goldberg, K. I. NMR Chemical Shifts of Trace Impurities: Common Laboratory Solvents, Organics, and Gases in Deuterated Solvents Relevant to the Organometallic Chemist. Organometallics 2010, 29 (9), 2176-2179.

(2) Malig, T. C.; Koenig, J. D. B.; Situ, H.; Chehal, N. K.; Hultin, P. G.; Hein, J. E. Real-Time HPLC-MS Reaction Progress Monitoring Using an Automated Analytical Platform. React. Chem. Eng. 2017, 2 (3), 309-314.

(3) Skórka, Ł.; Mouesca, J. M.; Gosk, J. B.; Puźniak, R.; Pécaut, J.; Maurel, V.; KulszewiczBajer, I. Towards Enhancing Spin States in Doped Arylamine Compounds through Extended Planarity of the Spin Coupling Moieties. J. Mater. Chem. C 2017, 5 (26), 65636569.

(4) Li, T. Y.; Su, C.; Akula, S. B.; Sun, W. G.; Chien, H. M.; Li, W. R. New Pyridinium Ylide Dyes for Dye Sensitized Solar Cell Applications. Org. Lett. 2016, 18 (14), 3386-3389.

(5) Kamino, B. A.; Morse, G. E.; Bender, T. P. Effect of Triarylamine Structure on the Photoinduced Electron Transfer to Boron Subphthalocyanine. J. Phys. Chem. C 2011, 115 (42), 20716-20723. 
NMR Spectra

${ }^{1} \mathrm{H}$-NMR 4-methoxy-N-(4-methoxyphenyl)-N-phenylaniline (4)

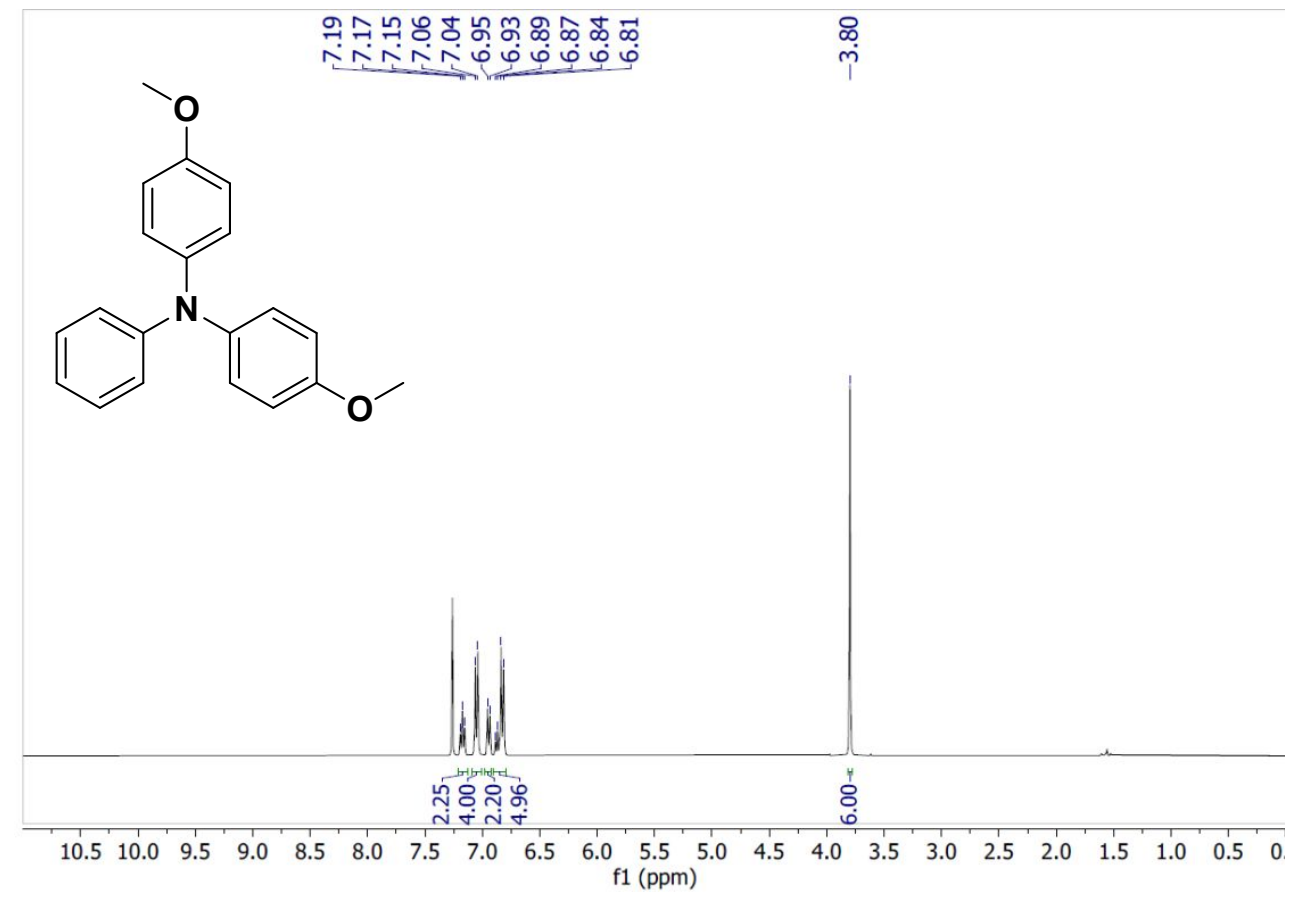

${ }^{13} \mathrm{C}$-NMR 4-methoxy-N-(4-methoxyphenyl)-N-phenylaniline (4)

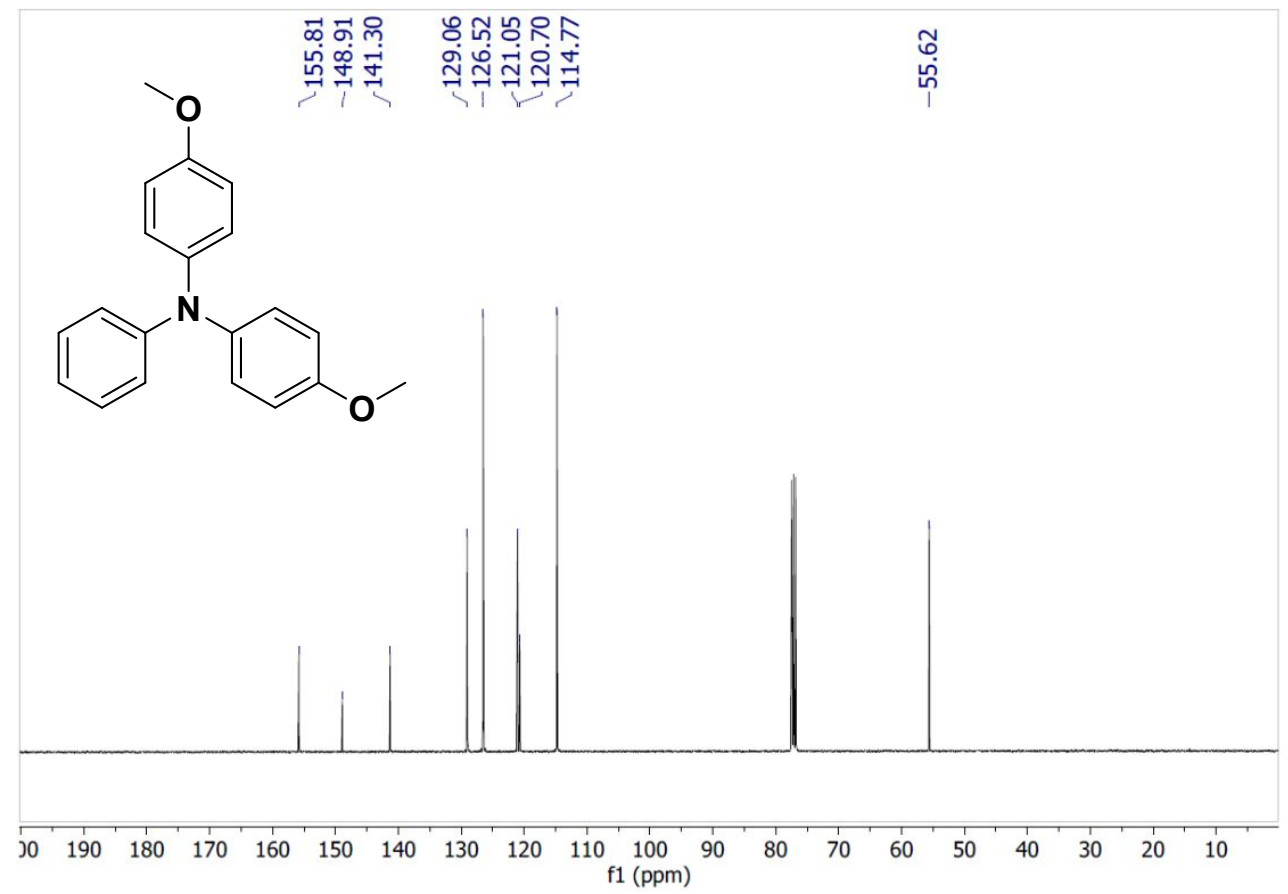


${ }^{1} \mathrm{H}-\mathrm{NMR}$ 4-bromo-N,N-bis(4-methoxyphenyl)aniline (6)

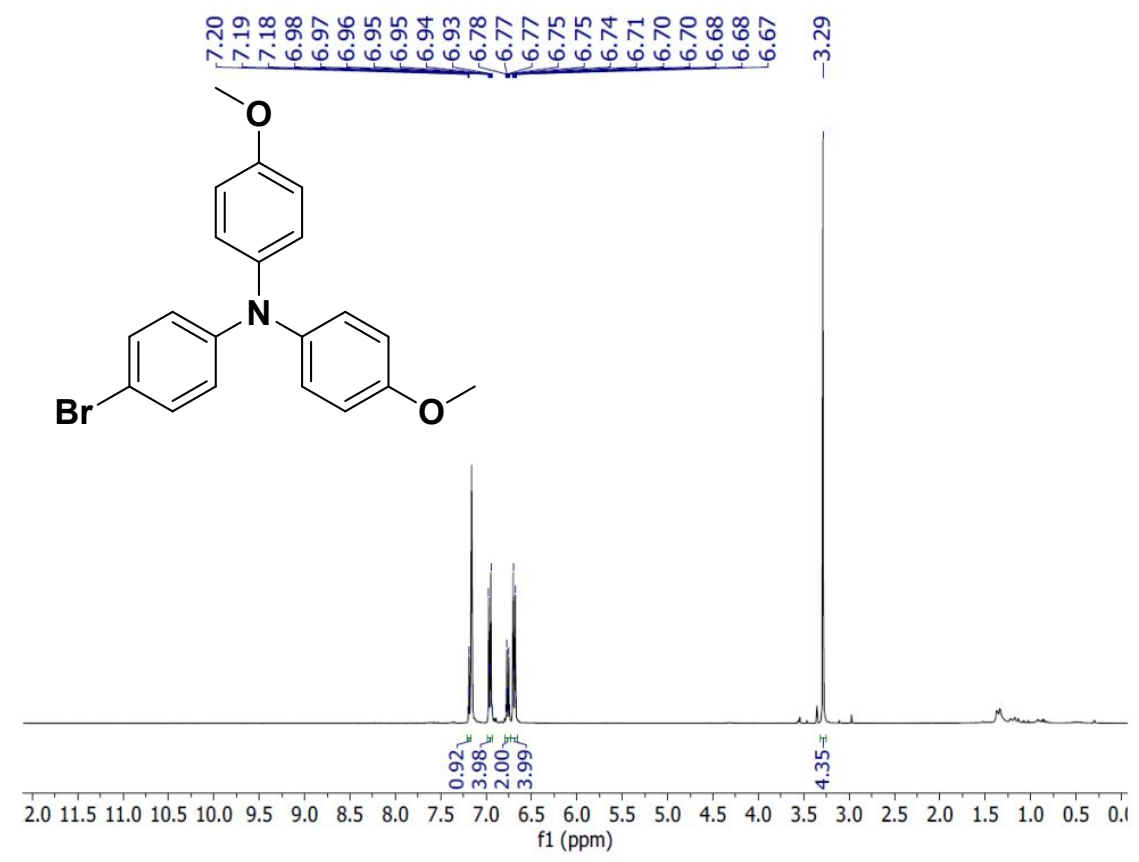

${ }^{13}$ C-NMR 4-bromo-N,N-bis(4-methoxyphenyl)aniline (6)

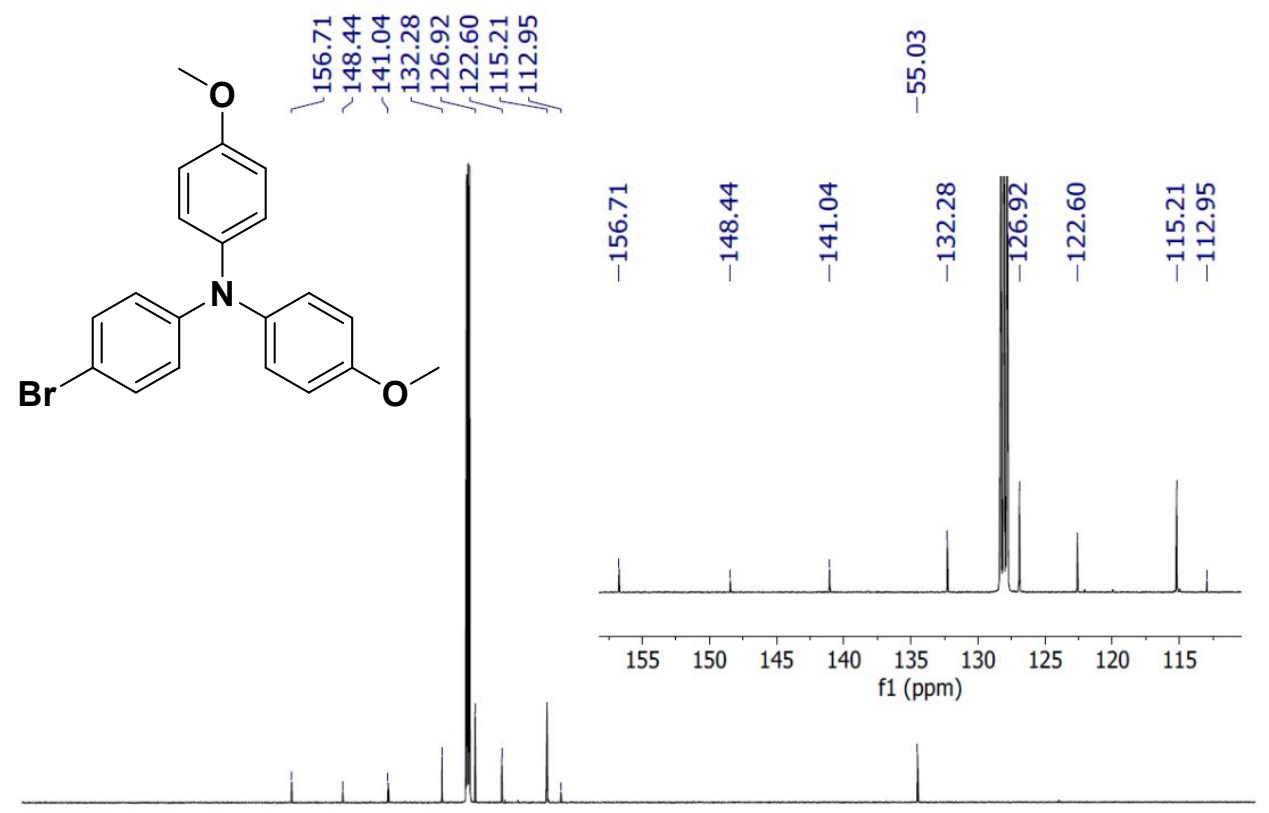

$\begin{array}{llllllllllllllllllll}00 & 190 & 180 & 170 & 160 & 150 & 140 & 130 & 120 & 110 & 100 & 90 & 80 & 70 & 60 & 50 & 40 & 30 & 20 & 10\end{array}$ 
${ }^{1} \mathrm{H}-\mathrm{NMR} \mathbf{N}^{1}, \mathbf{N}^{1}, \mathbf{N}^{4}, N^{4}$-tetrakis(4-methoxyphenyl)benzene-1,4-diamine (8)

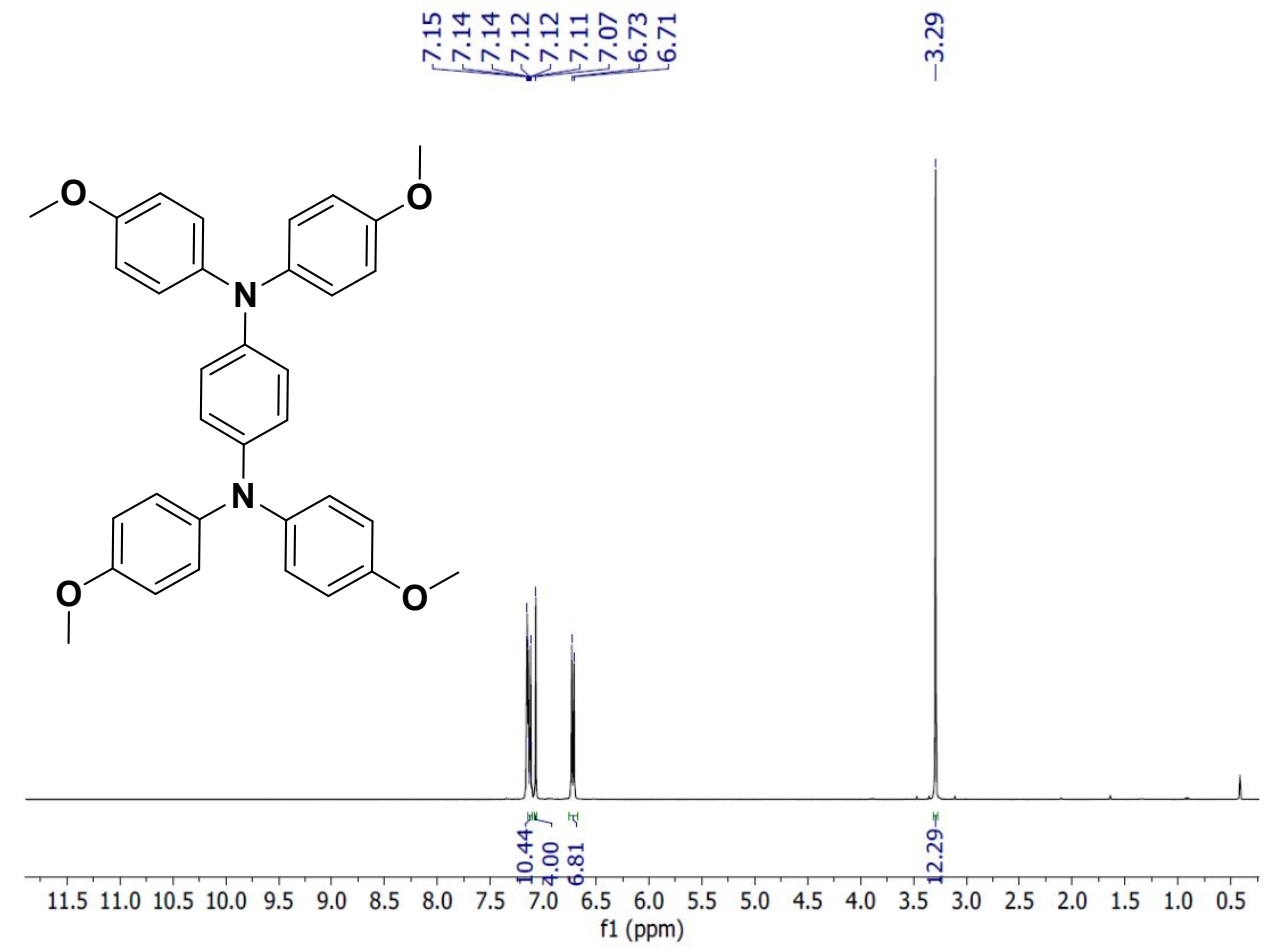

${ }^{13} \mathrm{C}-\mathrm{NMR} \mathrm{N}^{1}, N^{1}, N^{4}, N^{4}$-tetrakis(4-methoxyphenyl)benzene-1,4-diamine (8)

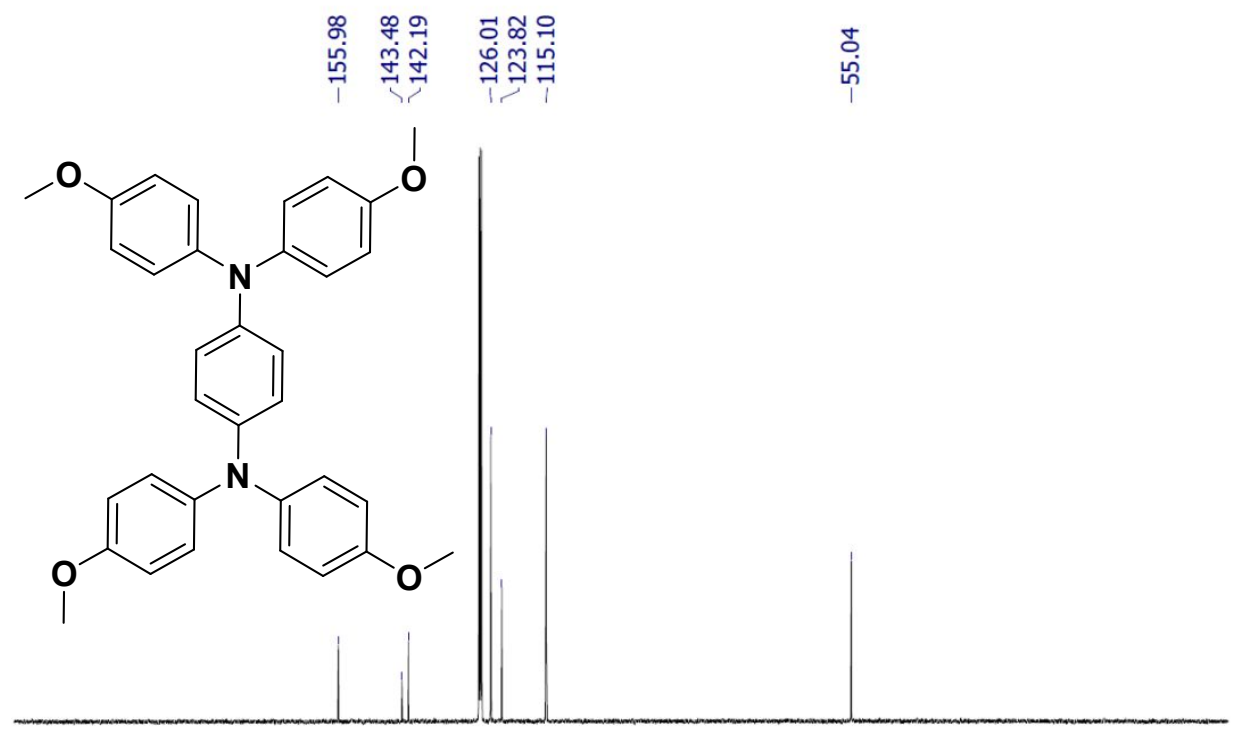

$\begin{array}{llllllllllllllllllllllllll}210 & 200 & 190 & 180 & 170 & 160 & 150 & 140 & 130 & 120 & 110 & 100 & 90 & 80 & 70 & 60 & 50 & 40 & 30 & 20 & 10 & 0 & -10\end{array}$ 